\title{
Monolithic substrate support catalyst design considerations for steam methane reforming operation
}

DOI 10.1515/revce-2016-0048

Received October 16, 2016; accepted March 10, 2017

\begin{abstract}
This paper reviews the research undertaken to study the design criteria that address the monolithic support structure requirements in steam reforming operation for the effective mass transfer of process gases to the active sites and effective conductive heat transfer through tube wall to the active catalytic areas, as well as low pressure drop operation. Design considerations include selection of substrate materials that possess good mechanical strength to withstand the severe reaction conditions and prevent catalyst crushing that would lead to carbon formation and catalyst deactivation, and excessive heating of the tube that results in hot spots which is fatal to tube lifetime. The support's mechanical properties are listed for the purpose of providing guidelines on verifying the structure durability. The practical aspect of packaging and stacking the monolith structures in the reformer tube for ease of loading and discharge is discussed to understand its readiness in industrial application.
\end{abstract}

Keywords: design considerations; monolithic catalyst; monolithic structure; monolithic support; steam methane reforming.

\section{Introduction}

Steam reforming of natural gas (methane) is a significant process in petrochemical plants and petroleum refineries. It is the most common pathway for producing hydrogen and synthesis gas (syngas, i.e. hydrogen + carbon monoxide) due to its cost effectiveness (Mohammadzadeh and Zamaniyan 2002, Zamaniyan et al. 2011, Saito et al. 2015)

\footnotetext{
*Corresponding author: Matthew James Watson, Department of Chemical and Process Engineering, College of Engineering, University of Canterbury, Private Bag 4800, Christchurch 8140, New Zealand, e-mail: matthew.watson@canterbury.ac.nz Luqmanulhakim Baharudin: Department of Chemical and Process Engineering, College of Engineering, University of Canterbury, Private Bag 4800, Christchurch 8140, New Zealand
}

as compared to other processes discussed by Baharudin and Watson (2017). In this review paper, a monolithic structured packing for steam methane reforming (SMR) reactor will be studied. This novel reactor packing offers the benefits of overcoming the heat conduction limitation in the current industrial-scale reformers, process intensification for an overall plant optimization, and materializing the concept of compact reformer. SMR is expressed by (Saito et al. 2015).

$$
\mathrm{CH}_{4}+\mathrm{H}_{2} \mathrm{O} \leftrightarrow \mathrm{CO}+3 \mathrm{H}_{2}
$$

In a nutshell, a monolithic structure is a single structure consisting of thin-walled narrow channels that are parallel to each other (Heck et al. 2001, Roy et al. 2004, Zamaniyan et al. 2011) for ease of reactants flow (Ryu et al. 2007). Due to the channels, the structure offers a pressure drop that is one to two orders of magnitude smaller than that of randomly packed pellets or beads in a packed bed (Ryu et al. 2007, Zamaniyan et al. 2011). In general, the monolithic catalytic system enhances the mass transfer effectiveness due to increased specific surface area and evenly distributed flow, and most importantly higher effectiveness of heat transfer for heterogeneous gas-solid catalytic reactions. These advantages can potentially result in lower investment and higher productivity for the production operations. In addition, a higher mechanical strength of the monolithic structure (Zamaniyan et al. 2011) has the potential of bringing down the operating costs through avoidance of frequent reformer shutdown and start-up for catalyst recharge due to breakage.

The main focus of this paper is to review the aspects of a SMR reactor where a monolithic catalytic system might be useful. The development of monolithic catalyst in SMR is an initiative to overcome the challenges faced by industrial-scale operation where performance gets affected due to the difficulty in achieving effective heat transfer from the external heat supply to the catalyst for this highly endothermic reaction. For the purpose of discussion throughout this paper, the heat transfer effectiveness is defined as the measure of effective utilization of the external heat supply by the catalytic system of the steam reformer, for better thermal efficiency of the system, and 
the potential for intensifying the process by increasing the extent of reactant conversion per unit volume of reactor.

A lot of interest has been shown in the area of process intensification (Giroux et al. 2005), and the application of monolithic catalytic system can be one of the means towards achieving it. In process intensification, the process volumes are reduced. There are two ways by which the process intensification initiative can be introduced. One, multiple unit operations are consolidated as a single unit. Two, a process unit size is reduced such as in the case of the monolithic reactor. Both initiatives offer the benefits of cost and weight savings. Additionally, the latter also offers a better thermal response to a transient behavior as a result of a smaller energy amount required to heat the smaller reactor (Giroux et al. 2005).

An example of an SMR process intensification study on multiple unit operations in a combined unit was conducted by Mei et al. (2007). In their study, a jacket metal monolith reactor containing two parts that couple an exothermic oxidation process with the endothermic SMR reaction was simulated. The first part is an inner pipe where the exothermic methane combustion took place over $\mathrm{Pd} / \mathrm{Al}_{2} \mathrm{O}_{3}$. The second is an annular part between the outer and the inner pipes where the endothermic SMR took place over $\mathrm{Ni} / \mathrm{Al}_{2} \mathrm{O}_{3}$, utilizing the heat generated from the exothermic combustion and thus avoiding the requirement for an external heat supply as in the conventional SMR reactor.

This review also places a focus on developing a compact reformer as a hydrogen supply distribution network infrastructure (Giroux et al. 2005), which can be made possible by process intensification through the application of a monolithic structured SMR with a reduced tube length. Commercialized automobiles utilizing hydrogen fuel cells would find convenience in a well-distributed hydrogen system. On the other hand, hydrogen fuelling stations with the infrastructure where hydrogen can be generated on site would be convenient for the hydrogen producers. The design of small-scale hydrogen fuelling station with on-site SMR applying the monolithic catalytic support system was developed and presented by Roh et al. (2010).

Based on the design presented by Roh et al. (2010), the monolithic catalytic system is found to be suitable for a compact reformer due to the prospect of a heat transfer enhancement across the catalyst bed and an improvement of the reactant accessibility to the active catalyst site, for better reaction performance and hydrogen production efficiency. For the industrial-scale reformers, the significant improvement in the radial heat transfer would introduce a possibility of enlarged reformer tube diameters for increased throughputs, which corresponds to reduced investment costs. In the current design, the reformer tube diameter is limited due to the ineffective reaction heat removal by convection of the process gas from the pelletized catalysts to the reformer tube walls. The tube diameter is limited as a design safety feature to eliminate the risks of temperature runaway, as a certain minimum process gas flow rate is typically required to prevent hot spots (Tronconi et al. 2014). A monolithic support also offers the benefits of attaining a minimum pressure drop at high throughput (Ryu et al. 2007) as well as achieving nearer approach to equilibrium of the reforming reaction at the reformer exit, allowing close to complete methane conversion (Mohammadzadeh and Zamaniyan 2002).

\section{Intensification of hydrogen manufacturing processes and challenges in industrial steam methane reforming operation}

In this section, the requirements in developing intensified hydrogen manufacturing processes with regards to compact steam reforming unit for hydrogen fuel stations are reviewed. It is followed by a brief discussion on challenges faced in industrial SMR operations. The discussion introduces monolithic substrate support structures and reviews the monolith's design considerations investigated by various researchers around the world.

\subsection{Small scale hydrogen manufacturing for fuelling stations}

With the dawning of fuel cell technologies, a compact reformer design is useful, and to materialize this, intensification of the hydrogen manufacturing process is required. In order to achieve high throughput, the desired gas hourly space velocity (GHSV) in a compact reactor is made possible with the employment of catalysts of a particular shape that can keep pressure drop at a minimum level. SMR over Ni catalyst supported on porous alumina pellets is limited in the transport of heat. This pelletized catalyst system is less efficient as it requires large reformer tube areas and thereby a big catalyst volume in order to receive the large amount of heat from the external supply at high temperatures (Ryu et al. 2007).

A large radial temperature gradient, whereby heat is flowing from the reformer tube wall to the center of the 
catalyst bed, is caused by this highly endothermic reaction. Especially at higher feed rates, the temperature gradient becomes steeper when the catalysts are active but their thermal conductivities are low (Roh et al. 2010). Therefore, heat transfer enhancement is required to increase the system's thermal efficiency in order to meet higher utilization of energy (Tonkovich et al. 2004).

Subsequently, in the case of developing a compact reformer, a large increase in the reformer furnace temperature becomes necessary for the catalysts bed temperature to be sufficiently high for the reaction to take place in a reduced reformer volume. A monolithic catalyst might potentially be the solution for this process intensification in order to achieve high heat transfer effectiveness and to avoid excessive firing of the furnace.

In general, the effectiveness factor of pelletized catalysts is lower for larger pellets due to a decreased availability of external surface area (Roh et al. 2010), which retards the diffusion of the process gas through the catalyst pore network to the catalyst sites. On the other hand, smaller pellets result in higher pressure drop in the reformer. Similarly for monolithic catalytic structure, a well-designed structure would enable striking a balance in the parameters, which will be discussed further in this paper.

In summary, developing compact reformers as hydrogen fuel stations for fuel cell vehicles requires an optimized balance of crucial parameters such as heat transfer and mass transport effectiveness while keeping the pressure drop of the reactor below a threshold value, in order to meet the desired GHSV and throughput.

\subsection{Industrial-scale steam methane reforming operation}

At an industrial scale, the SMR reaction occurs after desulphurization in the feed purification section for removing contaminants, especially sulphur, that are poisonous to the downstream catalysts.

Following the desulphurization, hydrocarbons such as natural gas or naphtha feed and steam are mixed prior to being fed to the reformer that consists of tubes filled with Ni pelletized catalysts (Mohammadzadeh and Zamaniyan 2002, Zamaniyan et al. 2011). Traditional ceramic media are used as the catalyst support. Maximization of surface area to enhance heat transfer and reactant gas accessibility to active catalyst sites is attempted by shaping the catalyst's support media in the forms of pellets, balls, small saddles, and "wagon wheels" (Whittenberger 2010). Reactions typically take place at the temperature range of between 500 and $950^{\circ} \mathrm{C}$ and operating pressure of
1500-3000 kPa (Mohammadzadeh and Zamaniyan 2002, Zamaniyan et al. 2011). The flue gas in the combustion chamber exiting the fired section is in excess of $1000^{\circ} \mathrm{C}$ (Czuppon et al. 1995). On the process side, a mixture of $\mathrm{CO}, \mathrm{CO}_{2}, \mathrm{H}_{2}$, and unreacted hydrocarbons and steam leaves (Mohammadzadeh and Zamaniyan 2002) the reformer for the subsequent process unit called shift reactor where the water gas shift reaction takes place. Here, the remaining carbon monoxide reacts with steam to further produce hydrogen.

The furnace is heated by operating the burners that supply heat to the reformer tubes via forced convection and radiation. There are several types of furnaces being used in the industry. The commonly used furnace types, categorized based on the configuration of the burners, are radiant wall/side-firing, terrace wall, down-firing, and upfiring. The reformer furnace typically contains between 40 and 400 tubes (Mohammadzadeh and Zamaniyan 2002), determined by the plant design capacity.

Depending on the type of furnace, the tube has an internal diameter ranging from 70 to $160 \mathrm{~mm}$, a wall thickness between 10 and $20 \mathrm{~mm}$, and an axial length between 6 and $12 \mathrm{~m}$. In a commercial plant, the tubes are typically made of nickel chromium alloy steel such as HK40 (Cr 25\%, Ni 20\%, and Co 4\%) and IN519 (Cr 24\%, Ni 24\%, Nb $1.5 \%$, and Co $3 \%$ ). The reliability of the tubes, which are supported from either the ceiling or the floor outside the furnace chamber, is crucial. Failures can result in loss of production as re-installation of new tubes results in significant downtime (Mohammadzadeh and Zamaniyan 2002). In fact, the reformer lifetime of typically 15 years is often determined by the tube reliability, which is related to the creep properties of the alloy.

The steam methane reformer works based on the principle that the energy for the highly endothermic reaction is received from the external firing of the burners through conductive heat transfer through the walls of the reformer tubes in the furnace (Zamaniyan et al. 2011) to the catalysts in the tubes. In general, in terms of the reaction efficiency, steam reforming requires a constant supply of heat. Unfortunately, this is restricted by the ineffective heat transfer and limited external surface area to reach active catalytic sites. The catalysts located right next to the reformer tube internal wall receive the heat effectively, but the catalysts located at the tube center do not, since the conduction is difficult. This compromises the intended efficiency of the reaction (Whittenberger 2010). In a pelletized catalyst system, the heat is transferred from the catalyst pellets near the tube wall to the catalysts residing in tube center via ineffective convection of the process gas (Ryu et al. 2007). Heat conduction 
via point-wise contact is almost negligible (Zamaniyan et al. 2010).

The other main challenge in the industrial reformer is the formation of undesired carbon that can lead to excessive heating of the reformer tubes and result in hot spots that are fatal to tube lifetime. In addition, the catalyst loses its activity resulting in non-optimal reforming conversion. Carbon formation could occur due to

(i) flow restrictions in reformer tubes due to plugging,

(ii) too low steam during a plant upset,

(iii) sulphur poisoning (due to failure of the feed purification section) that causes catalyst deactivation.

Flow restrictions happen due to catalyst breakage as a result of reformer tube contraction and expansion, hydrocarbon contamination in nitrogen circulation during startup, and thermal shock induced catalyst breakage caused by liquid water carryover hitting the catalyst while it is hot. Therefore, the reformer tube plugging is partly related to the poor mechanical property of the pelletized catalyst system.

During the cycles of plant start-up and shutdown, the different rates of thermal expansion of the reformer tube metal and the ceramic support of the catalyst pellets introduce the tendency for catalysts to crush and break into fragments and powder. The ceramic medium, which does not expand to the same extent as the reformer tube during heating, settles a bit during tube expansion, and a portion is crushed to fragments and powder when the tube contracts during shutdown. Accumulation of catalyst support fragments and powder eventually plugs the reactor (Whittenberger 2010) and creates a flow restriction for the process gas. To make things worse, the broken catalysts plugging the tube along the axial direction are not uniform and form localized hot spots.

The clogging by broken catalysts requires removal and replacement of the media in the frequency of three to five years. The recurrence of this event imposes a substantial adverse impact to plant lifecycle. The catalysts replacement comes with considerable costs such as labor costs, loss of production opportunity during plant downtime, and costs to dispose the nickel catalyst, which is categorized as hazardous waste (Whittenberger 2010). This brings about the requirement for a catalyst support structure that has great mechanical strength with an equivalent thermal expansion rate to the reformer tube. Therefore, the selection of the monolithic support substrate material needs to be given reasonable consideration when designing the system to substitute the pelletized catalysts system, which will be covered later in this review paper.

\section{Monolithic support catalyst}

In the previous sections of this review, it has been established that monolithic catalyst supports in SMR require effective heat and mass transfer, low pressure drop, and good mechanical strength. Prior to going into detail on the requirements for monolithic catalyst supports, the structure of the support itself will be reviewed in this section. A monolith, as presented earlier, is a single structure composed of a number of narrow interconnected repeating thin-walled cells and channels (Heck et al. 2001, Roy et al. 2004, Zamaniyan et al. 2011) that provide pathways for ease of reactant flow and a pressure drop less than that obtained with packed beds by one to two orders of magnitude (Ryu et al. 2007, Zamaniyan et al. 2011).

\subsection{Characterization of monolith's physical geometries}

The physical characteristic of importance when using monolithic structures as the support for catalysts is the channel size for the passage of reactant and product gases (Heck et al. 2001). The characteristics of the monolith's macro-structure are geometrically defined by a standard expression called cells per square inch (CPSI). CPSI is determined collectively by the number of channels, their diameter $\left(\mathrm{d}_{\mathrm{ch}}\right)$, and the void fraction $(\varepsilon)$ of the structure known as open frontal area (OFA) (Zamaniyan et al. 2010), which provides information on the wall thickness. The aforementioned characteristics are used in the calculation of geometric surface area (GSA), which is the summation of all the channel wall areas (Heck et al. 2001) defined by the combination of CPSI and wall thickness (Zamaniyan et al. 2010) and is a key parameter for pressure drop and reactions controlled by mass transfer. Typically, CPSI is in the range of 100-1200, while $\varepsilon$ and wall thickness vary from 0.5 to 0.9 and 0.006 to $0.05 \mathrm{~cm}$, respectively (Roy et al. 2004), depending on a particular application. Hence, the solid phase (catalyst support weight) and $\varepsilon$ can be optimized in the monolith.

The shape of the cells and channels of a monolithic structure needs to be designed in such a way that it has a low pressure drop and high external surface area, where all parts of the external surface are exposed to the gas flow for higher conversion (Heck et al. 2001). The ratio of channel length and its diameter requires optimization to ensure that gas flow is distributed evenly through each channel while maintaining sufficient surface area for catalyst particles. The pressure drop is optimized in the monolithic structure between channel size (bigger-sized 
channel, lower pressure drop, and lower surface area) and void fraction of the monolithic substrate (higher void and lower pressure drop), without jeopardizing the mechanical strength of the monolithic structure. Various possible channel shapes are shown in Figure 1 (Zamaniyan et al. 2010).

\subsection{Monolithic substrate materials}

In general, ceramics or metals are the most commonly used materials for the manufacturing of monolith support structures. Monoliths made of plastics have also been exhibited, but will not be considered in this review as they do not possess suitable properties to withstand severe reaction conditions, as well as the capability for heat transfer management. Other material selection criteria when considering specific applications include cost and weight (Heck et al. 2001).

A monolithic structure such as honeycomb can be made of ceramics like cordierite or metals like iron/chromium alloy, $\mathrm{FeCr}$ alloy (Fe 72.8/Cr 22/Al 5/Y 0.1/Zr 0.1). These substrate materials exhibit excellent resistance to oxidation at elevated temperatures (Giroux et al. 2005). Cordierite ( $2 \mathrm{MgO} 2 \mathrm{Al}_{2} \mathrm{O}_{3} 5 \mathrm{SiO}_{2}$ ), an extruded multi-cell ceramic of low thermal expansion, was the substrate of choice of the monoliths used in the US's first large-scale catalytic converter installed in new vehicles, taking advantage of the material's property of high resistance to thermal shock fracture (Heck et al. 2001). Other substrates of metal monolith are typically aluminium, stainless steel, $\mathrm{FeCr}$ alloy, and other comparable alloys. Aluminium is only good for application in mild temperatures well below its melting point of $660^{\circ} \mathrm{C}$. Between metal and ceramic monoliths, the possibility of fabricating thinner walls is greater for metal where the OFA can approach $90 \%$. This would allow bigger $d_{c h}$ and hence offer even lower pressure drop at an equal or greater GSA. Figure 2 shows some typical ceramic and metal monoliths in the form of honeycomb, foams (Heck et al. 2001), and sheets (Giroux et al. 2005).

Listed in Table 1 are thermal and mechanical properties of possible monolithic support substrate materials: alumina, cordierite, and carbon steel, for the purpose of making judgement on which substrate material class is suitable for the selection in an application in a steam reformer. The reformer tube material IN519 is used as a basis for relative comparison with the monolithic substrate materials in terms of the thermal conductivity and the coefficient of thermal expansion (CTE). The three substrate materials are used in this comparison for the following reasons: alumina is a typical support material in the
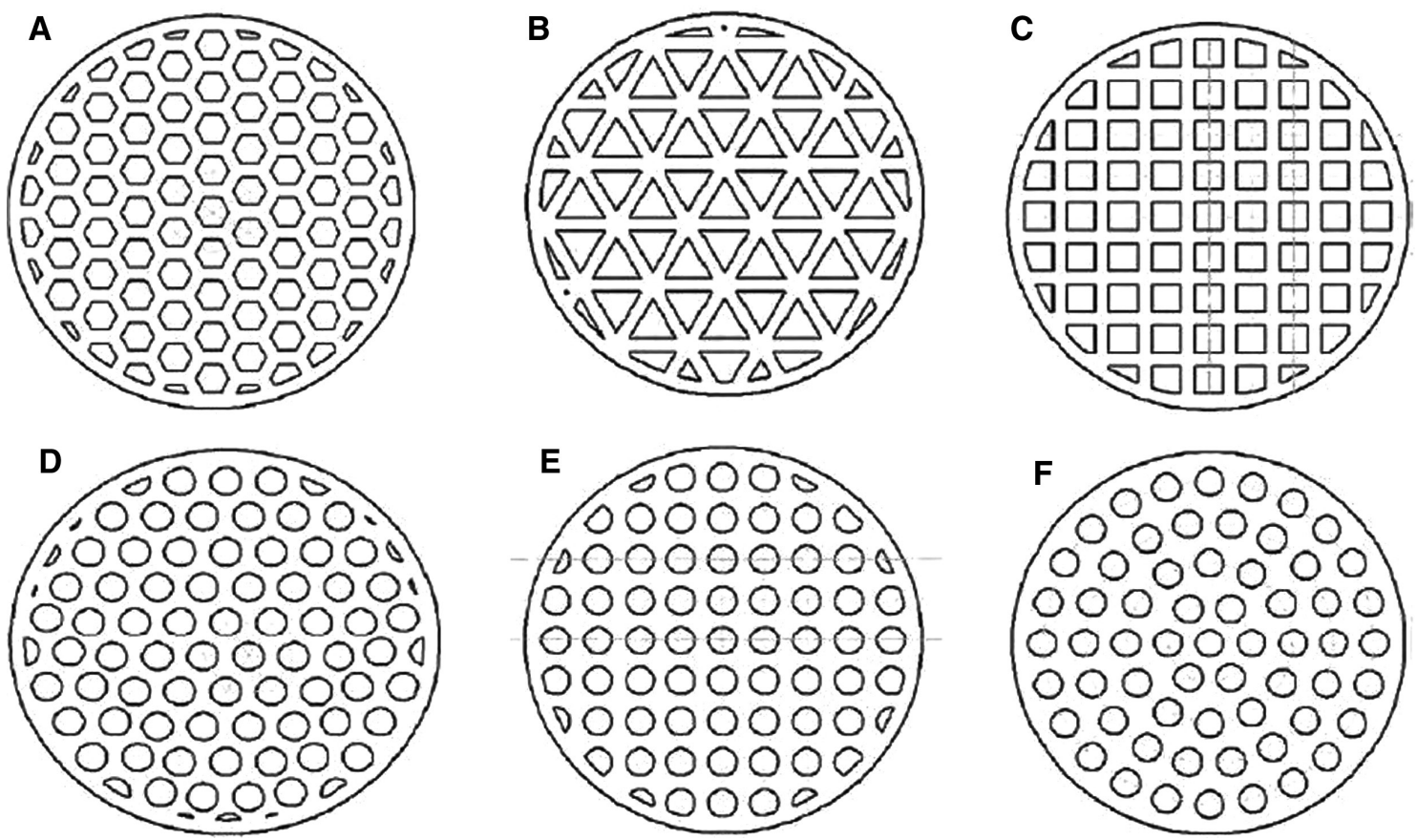

Figure 1: Various shapes and arrangements of monolithic support channel.

(A) hexagonal-shaped, (B) trigonal-shaped, (C) square-shaped, (D) circular-shaped, triangular arrangement, (E) circular-shaped, square arrangement, (F) circular shape, circular arrangement (Zamaniyan et al. 2010). Reproduced with permission from Elsevier. 

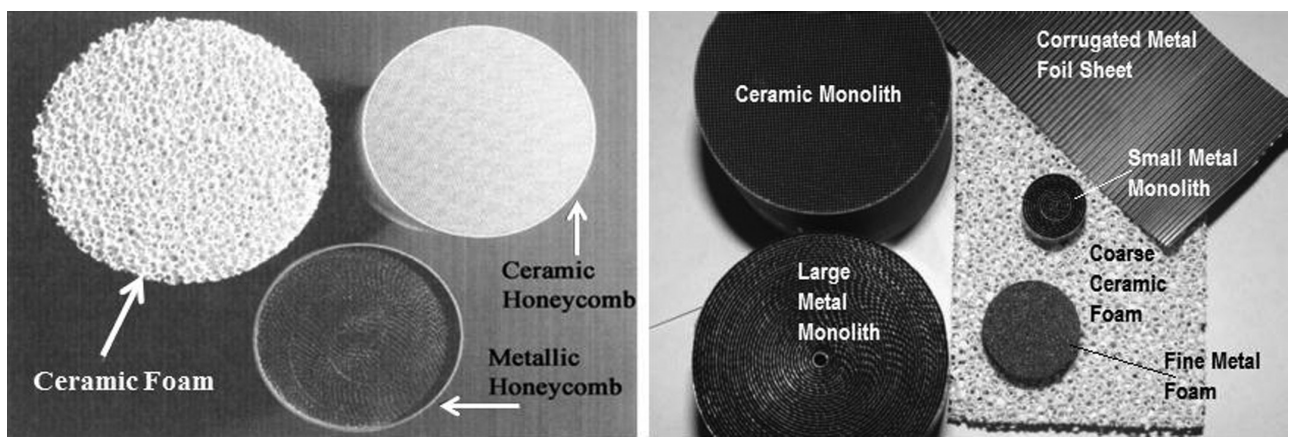

Figure 2: Various types of ceramic and metal monoliths [Heck et al. (2001) (left image); Giroux et al. (2005) (right image)]. Reproduced with permission from Elsevier.

Table 1: Thermal and mechanical properties of typical ceramic and metal materials used as supports in catalytic systems in comparison to the properties of a typical reformer tube material, IN519.

\begin{tabular}{|c|c|c|c|c|c|c|}
\hline & $\begin{array}{r}\text { Thermal conductivity } \\
\text { (W/mK) }\end{array}$ & $\begin{array}{r}\text { Coefficient of thermal } \\
\text { expansion (CTE) }(\mu \mathrm{m} / \mathrm{mK})\end{array}$ & $\begin{array}{l}\mathrm{CTE}_{\text {substrate }} / \\
\mathrm{CTE}_{\text {tube }}\end{array}$ & $\begin{array}{r}\text { Tensile strength } \\
(\mathrm{MPa})\end{array}$ & $\begin{array}{r}\text { Young's modulus } \\
(\mathrm{GPa})\end{array}$ & $\begin{array}{l}\text { Weibull } \\
\text { modulus }\end{array}$ \\
\hline IN519 & $12.7^{\mathrm{a}}$ & $17.1^{\mathrm{a}}$ & & & & \\
\hline Alumina & $35^{b}$ & $5.5^{\mathrm{b}}$ & 0.32 & $280^{c}$ & $395^{\mathrm{b}}$ & $10^{\mathrm{b}}$ \\
\hline Cordierite & $3^{c}$ & $1.7^{\mathrm{c}}$ & 0.1 & $25.5^{c}$ & $70^{c}$ & $4.2^{\mathrm{d}}$ \\
\hline Carbon steel & $50^{\mathrm{e}}$ & $13^{e}$ & 0.76 & $1095^{f}$ & $208^{f}$ & Very large ${ }^{g}$ \\
\hline INCOLOY ${ }^{\circledR} 800 \mathrm{H} / 800 \mathrm{HT}$ & $11.5^{\mathrm{h}}$ & $14.4^{\mathrm{h}}$ & 0.84 & $536^{\mathrm{h}}$ & $196.5^{\mathrm{h}}$ & NA \\
\hline INCONEL ${ }^{\circledR} 625$ & $9.8^{\mathrm{h}}$ & $12.8^{\mathrm{h}}$ & 0.75 & $965.3^{h}$ & $206.2^{\mathrm{h}}$ & NA \\
\hline HAYNES $^{\circledR} 230$ & $8.9^{i}$ & $16.1^{\mathrm{i}}$ & 0.94 & $839^{i}$ & $211^{i}$ & NA \\
\hline
\end{tabular}

Each property value presented is an average of typical values at room temperature. NA indicates unavailable information.

aINCO Europe Limited (1976).

${ }^{b}$ Auerkari (1996).

'Material Properties Charts (2013).

${ }^{\mathrm{d}}$ Martinez et al. (2008).

eHyperPhysics Online Database.

'Materials Data Book, Cambridge University Engineering Department (2003).

${ }^{\mathrm{g}}$ Askeland et al. (2010).

${ }^{\text {hS}}$ Special Metals Corporation.

'Haynes International.

pelletized catalysts, cordierite is a typical ceramic material used as a monolithic support structure, and carbon steel is a typical metal substrate that could potentially be fabricated as a monolithic support structure. The products from Special Metals Corporation, INCOLOY ${ }^{\circledR} 800 \mathrm{H} / 800 \mathrm{HT}$ and INCONEL ${ }^{\circledR} 625$ are included as the potential superalloy candidates for fabricating the metal monoliths, while HAYNES $^{\circledast} 230$ is added as one of the candidates from Haynes International's portfolio of high-temperature alloys, for the purpose of making the comparison among some of the metal alloys commercially available in the market.

Based on the properties listed in Table 1, for the purpose of selecting the material that has good mechanical properties for sustainability in the harsh reaction condition of SMR, metal substrate appears to be the better candidate for the monolithic support, when compared with ceramics. In addition, metal (i.e. carbon steel in this comparison) as the monolith also has higher thermal conductivity for more effective radial conduction of heat from the reformer tube to the catalytic active sites. Most importantly, metals generally have a CTE closer to the coefficient of the tube material, which is vital for the reformer operation that is subject to heating and cooling from time to time.

However, the metal substrates have a disadvantage in comparison to the ceramics when it comes to the compatibility between the monolith materials and the catalyst washcoat materials. Catalyst washcoat, which is the layer deposited on the walls of the geometric surface of the monolithic structure, comprises a high surface area 
carrier of typically an inorganic oxide such as alumina, stabilizers, and a dispersion of active metal or metal oxide catalyst particles (Heck et al. 2001, Giroux et al. 2005).

The material selection for the monolithic substrate affects the adhesion of the catalyst layer washcoating to the walls and channels of the structure. Decent anchoring between the washcoat and the monoliths support materials is ensured by the porosity of the substrate material (Giroux et al. 2005). A brief comparison between the SEM images (Figure 3) of a bare cordierite (Nijhuis et al. 2001) and a bare FeCr alloy (Rallan and Garforth 2014) reveals a highly distinctive surface morphology between the two substrate materials. The cordierite possesses a highly porous surface which promotes a stronger adhesion bonding with the washcoat layer (Nijhuis et al. 2001), in comparison to the $\mathrm{FeCr}$ alloy.

For the ceramic monolithic support such as cordierite, the precious catalytic metal in the washcoat does not usually migrate into the support, and vice versa. This stays true even in the harsh conditions where steam content is high and sulphur is present and in a reducing environment. For the monoliths made of a metal, their compatibility with the catalyst washcoat in terms of the CTE must be considered. A poor adhesion is highly possible during thermal cycles if the compatibility of the CTE of the two materials is not satisfactory. In addition to the washcoat adhesion issue, metals or alloys may have components that are not stable in quick and extreme temperature changes during transitioning from shutdown and start-up to normal operation, where they could potentially migrate into the catalytic washcoat and hence poison the catalyst shortly after the operation commences (Giroux et al. 2005).
For the purpose of using a metal as the substrate material for monolith supports in the SMR reaction, the washcoat materials for the deposition of the active catalyst particles onto the monolithic structure require special attention in terms of material selection and coating technique. This will be a separate topic of discussion. In general, the preparation methods of the washcoat follow the typical synthesis of pelletized catalysts. Further reference can be made to the articles by Nijhuis et al. (2001) on the effective washcoating techniques on the surface of cordierite; Echave et al. (2013) on metal monoliths that include aluminium, $\mathrm{FeCr}$ alloy, and brass; and Basile et al. (2008) on FeCr alloy foam.

\subsection{Classification of monolithic catalysts}

Zamaniyan et al. (2011) has classified monolithic catalysts into two general categories: washcoated monolithic catalyst (WMC), which has an active phase coated on the structured support as defined earlier in Section 3.2, and bulk monolithic catalyst (BMC), where the body of the monolith itself is made of intrinsically active material for the intended catalytic reactions. In all the catalytic investigations of monolithic structures, WMC has been the approach employed by the researchers, especially for the reforming reaction.

The utilization of BMC as the catalysts has been demonstrated in the hydrocarbon decomposition reaction to produce carbon nanomaterials and hydrogen. Chinthaginjala et al. (2008) demonstrated hydrocarbon decomposition, which is also a catalytic route to produce hydrogen
A

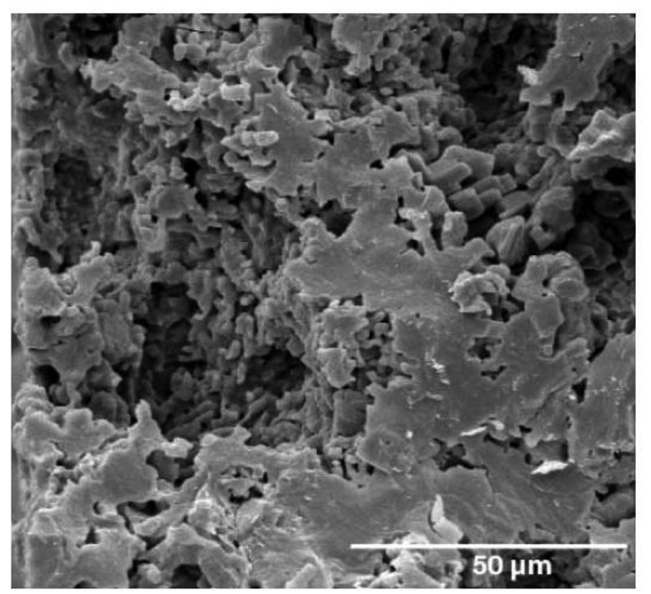

B

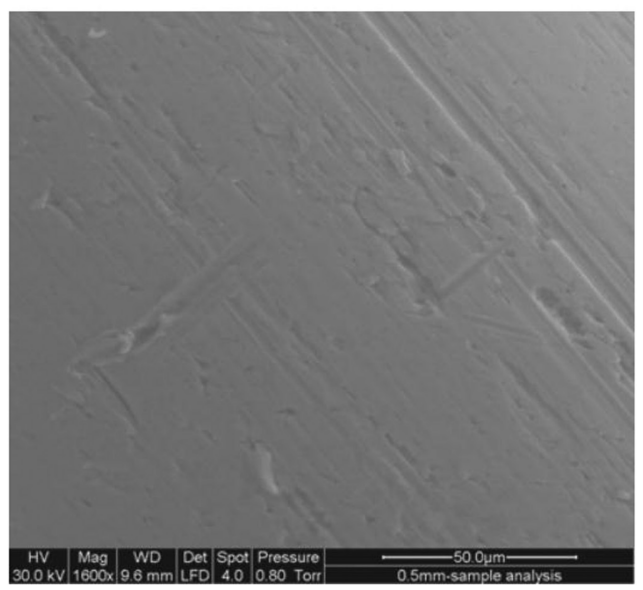

Figure 3: SEM image of bare substrate's surface.

(A) Cordierite (Nijhuis et al. 2001). Reproduced with permission from Taylor \& Francis; (B) FeCr alloy (Rallan and Garforth 2014). Reproduced with permission from Elsevier. 
(Baharudin and Watson 2017), for carbon nanofibers (CNF) synthesis over a Ni foam as the BMC. The growth of CNF took place on the BMC itself. While having the advantage of not requiring to washcoat the structure surface with metal nanoparticles deposition, BMC is not suitable for application in SMR due to the potential encapsulation by a carbon layer on the monolithic catalyst surface that will deactivate the catalytic system.

In comparison to $\mathrm{BMC}$, there is no doubt that $\mathrm{WMC}$ is more complicated in terms of preparation as adhesion of the washcoat layer may introduce non-uniformity in the structure and the thickness, as well as inhomogeneity of the catalytic metal particles dispersion on the washcoat (Zamaniyan et al. 2011).

\subsection{Advantages of monolithic structures}

A large OFA of the monolithic structure made by the channels introduces very little resistance to flow if not negligible, hence the benefit of low pressure drop. As a result of the lower pressure drop, the system's back pressure is lower, which in turn decreases the energy loss (Heck et al. 2001).

In addition, monolithic structures have the potential to offer good mechanical strength in comparison to the pelletized catalysts that are prone to attrition leading to tube blockage. The catalyst attrition is caused by the pressure due to packed bed weight, or the fact that the catalysts are present in a harsh chemical environment at high temperature and pressure, as well as quick and extreme temperature changes during transitioning from normal operation to shutdown and start-up. All these factors lead to deterioration of the catalysts activity, on top of the system suffering from increasing pressure drop (Giroux et al. 2005).

Due to the connected nature of the cellular structure of the monolithic support, the radial heat transfer via conduction from the tube wall to the catalyst is improved, as well as accessibility of process gas to the active catalyst sites, which is vital for high-temperature, diffusion-limited reactions. In a conventional packed bed reactor, the radial conduction is as good as negligible where heat is transferred by the point contact of one catalyst pellet with another (Ryu et al. 2007).

\subsection{Disadvantages of monolithic structures and initiatives for their improvement}

Successful demonstrations of the application of monoliths as a support in automobile catalytic converters have sparked considerable interest among industries to follow this step in the design of pollution abatement systems and other industrial applications. However, the system comes with drawbacks that may prevent it from widespread industrial use beyond environmental applications, which have been identified as below.

One disadvantage that prevents the widespread adoption of monoliths in SMR operations is the resistance of heat transfer at the gap of the interface between the monoliths and reformer tube internal wall. A design of suitable packaging method to address this issue was presented by Tronconi et al. (2004) and will be discussed in the next section on monolithic support structure design considerations.

In addition, in many exothermic and endothermic reactions in chemicals and petroleum processing plants, temperature is the main factor that governs the selectivity. The parallel channels of the monoliths make the structures behave like an adiabatic reactor, making temperature control difficult. However, metal foams can be an option to control the temperature in order to overcome this shortcoming (Heck et al. 2001).

Metal foam has a sponge-like structure as shown in Figure 4 (Twigg and Richardson 2002). The structure is made of solid struts that connect the spherical-like cavities (the cells) through openings or windows (the pores). The radial mixing not possible in the honeycomb monoliths due to segregated flow in parallel channels is made possible in the open-celled foam structures, preventing non-uniform distributions of the reactants over the cross section of the reactor. In addition, the foams' continuous thermally connected structure offers a mechanism for further enhanced radial heat transfer as compared to the honeycomb monoliths in non-adiabatic reactors, where the temperature gradients in both radial and axial directions can be reduced, and hence, the possibility of hot spots is minimized. However, the derivation of reliable

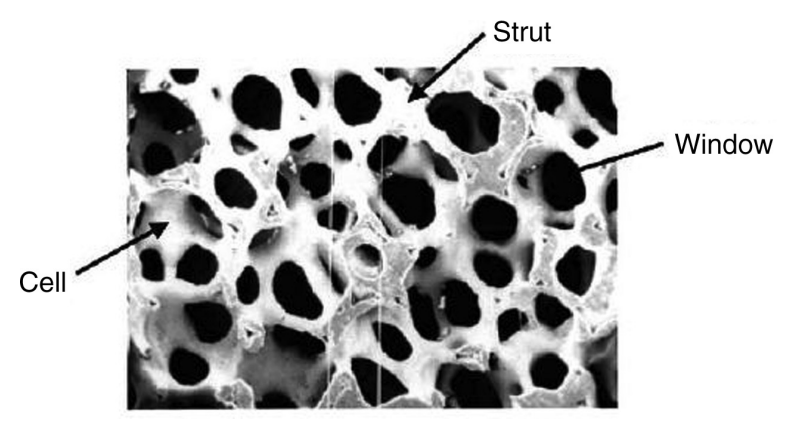

Figure 4: Micrograph of the cells, windows, and struts of a foam structure (Twigg and Richardson 2002).

Reproduced with permission from Elsevier. 
engineering correlations for the prediction of the heat transfer rates in foams is a challenge (Tronconi et al. 2014).

The honeycomb monoliths on the other hand would allow a systematic approach to design the structure's geometries (i.e. CPSI, void fraction, and channel size and shape) with a minimized mass transfer resistance and heat transfer resistance, at an optimally low pressure drop and acceptable mechanical strength. The engineering design correlations for the honeycomb monolithic structure will be discussed in detail in Section 4. Various attempts have been made to overcome the shortcomings of honeycomb monoliths in applications where the reaction temperature control is crucial for the selectivity of the products. For further reading, reference should be made to a comprehensive discussion by Tronconi et al. (2014) presenting some current developments in this area, covering various heat transfer performance investigations in selective oxidation processes, strongly exothermic Fischer-Tropsch synthesis, and exothermic CO hydrogenation processes.

In order to achieve the desired conversion efficiencies, the monolith needs to contain sufficient catalyst (Heck et al. 2001), which is an important aspect to study when developing the monolithic catalytic support for SMR. A demonstration of the requirement of higher catalyst loading in the coating layer to enhance the performance of SMR was presented by Giroux et al. (2005), where the same amount of catalyst was loaded in a washcoat layer on monolith of cell density of 400 CPSI $\left(2795 \mathrm{~m}^{2} / \mathrm{m}^{3}\right.$ and channel widths $1.1 \mathrm{~mm})$ and 200 CPSI $\left(1890 \mathrm{~m}^{2} / \mathrm{m}^{3}\right.$ and channel widths $1.4 \mathrm{~mm}$ ). Although the thickness of the washcoat layer was increased on the latter by a factor of 1.5 , the catalyst performance was essentially the same due to the same amount of catalyst being deposited onto the washcoat layers in both monoliths. A higher catalyst particle loading amount is required for the diffusion to have more impact on the overall process.

However, the catalyst amount deposited on the walls of monoliths of a given volume is much less in comparison to small pellet sizes. To achieve higher catalyst loading, high surface area structure such as fins, foam, and corrugated foils can be used to create surface area enhancement. Alternatively, adding a more active catalytic component in the coating layer or increasing loading of catalyst particles in the coating layer can be applied (Giroux et al. 2005). A combination of increased surface area, catalyst activity, and catalyst loading is expected to be the most effective. This leads to the idea of layering the monolithic structure with highly porous materials to produce improved dispersion of metal catalyst particles on the monoliths surface for reaction efficiency, which is covered briefly in this paper but a separate subject altogether for an in-depth discussion. Our group is currently working on the combination of these factors by synthesizing carbon nanotubes growth on metal foam.

An alternative solution to achieve high catalyst loading deposited on the monolith structure is presented by Visconti et al. (2016) by exploiting the high surface area per unit volume of the foam structures. A metal foam typically has open accessible pores that provide the surface for loading the catalytic components in the range of 10100 per inch, and an interconnecting porosity in the range of $75 \%-90 \%$ or higher (Twigg and Richardson 2002, Tronconi et al. 2014). The high surface area per unit volume enhances the interaction between the reactants and the catalysts coated on the foam struts (Tronconi et al. 2014).

More interestingly, instead of employing the typical technique of washcoating the catalysts on the foam struts, Visconti et al. (2016) experimentally demonstrated a higher amount of catalysts loading by directly filling the voids of the foam with randomly packed small catalyst pellets, which they termed as "packed foam", as shown in Figure 5. The same amount of the catalyst pellets as in a randomly packed bed was packed in the foam voids in order to make a fair experimental comparative study of the heat transfer performance, and simulated structure of open-cell foam typically washcoated on the struts was also included in the comparison. A superior overall heat transfer coefficient was obtained in the case of packed foam, which revealed the void packing technique as being capable of "killing two birds with one stone": maximizing the amount of catalyst loading for reaction efficiency and enhancing the overall heat transfer performance. In addition, this technique eliminates the adhesion problem when washcoating the catalyst on the metal surface. Notably, the small pellet catalysts packed in the voids of the foam result in an increase in pressure drop due to reduced porosity of the foam leading to an increased resistance to flow, and therefore, a balanced trade-off between the catalyst loading amount, the heat transfer performance and the pressure drop is required.

\section{Design considerations for developing monolithic catalytic support for steam methane reforming}

Based on the challenges in SMR operation discussed earlier, the catalyst breakage in pelletized systems needs to be addressed by an improved mechanical strength of 

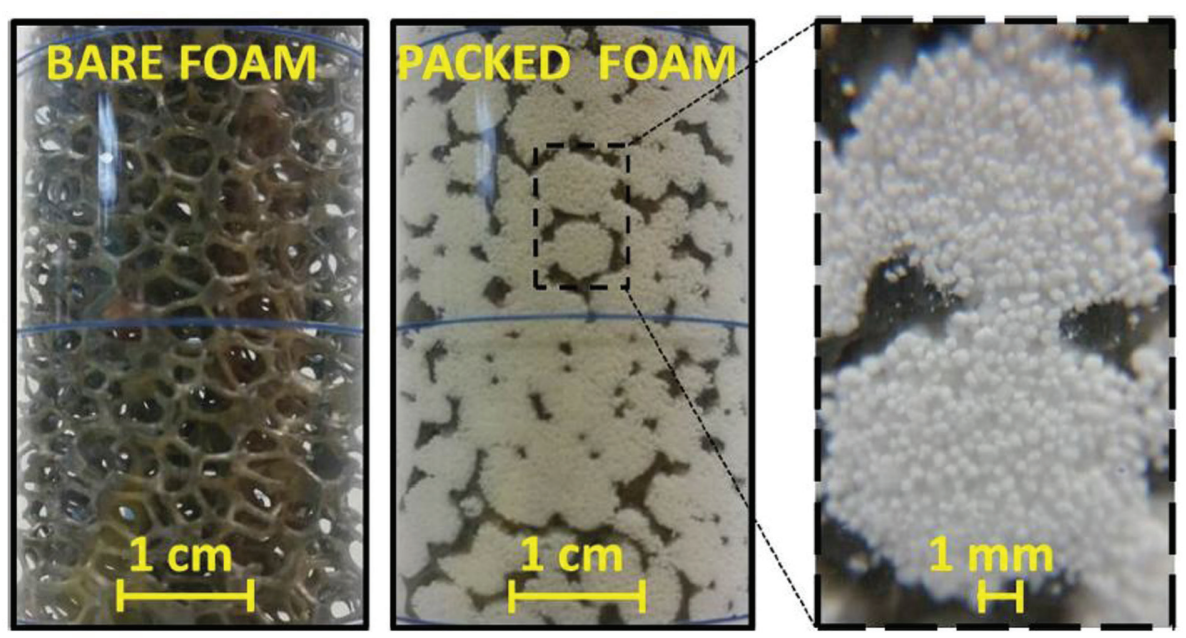

Figure 5: (Left) Bare foam structure typically washcoated with active catalysts. (Right) Packed foam filled with small pellet catalysts in its void (Visconti et al. 2016). Reproduced with permission from Elsevier.

the monolithic support structure especially because radial temperature gradients are significant near the process gas inlet of the reformer tube.

Towards achieving process intensification, smaller vessels result in a reduced capital cost, while lower pressure drop through the monolithic structure results in an overall improved energy efficiency. Process intensification allows the possibility of a smaller number of larger diameter and shorter reformer tubes too.

The primary design consideration while designing the monolithic support is the selection of the substrate material. Besides having good mechanical strength to avoid catalyst crushing that leads to carbon formation, catalysts deactivation, and eventually hot spots, the substrate material of choice must have high surface area through porosity and voidage to provide the accessibility to active catalyst sites. For the purpose of allowing access of process gases to the active sites, material selection of the active catalyst and its coating strategies and thickness on the support structure need to also be put into consideration. Additionally, determining the support's optimized channel shape, number, and size for low pressure drop and maximum gas access to catalyst active sites at the external surface area is also crucial for the diffusion-limited reaction.

Regardless of whether it is about designing a compact reformer for hydrogen fuel cells or hydrogen-transport refuelling station or trying to overcome the operating challenges of a reformer discussed earlier, certain design considerations need to be taken into account while developing monolithic catalytic supports so that effective reactions can take place at minimal operational disruption. In this section, the research undertaken to study the design criteria that address the monolithic catalytic support requirements for effective mass transfer of process gas to the active sites, effective conductive heat transfer through tube wall to the overall active catalytic areas, low pressure drop operation, mechanical strength of the support structure, and packaging into the reformer tube for ease of loading will be reviewed. In this way, monolithic structure design guidelines can be established.

\subsection{Effective mass transfer}

In a monolithic catalytic structure, there are two established types of mass transfer limitations. The first is bulk mass transfer of process gas from the gas phase to the monolithic structure's surface, and the next is diffusion of the reactants through the monolith's microporous structure to the catalytically active metal sites.

\subsubsection{Bulk flow distribution of process gas}

In a conventional pelletized catalyst system, the pellets are designed to achieve high GSA per unit volume by reducing the size of the pellets. However, this increases the pressure drop of the catalyst bed, unless the macroporosity of the bed is increased. This brings about the design of pellet shapes with one or more holes, in order to provide higher bed porosity, but the pellets' mechanical strength is jeopardized. Therefore, catalyst vendors compete in making shapes that optimize these parameters, by increasing the external surface area using multiple holes and various pellet shapes (Zamaniyan et al. 2011), to lower the pressure 
drop while preserving adequate mechanical strength of the pellets.

When designing reactors using monoliths, the entrance bulk flow distribution needs to be given fair consideration. It is therefore crucial to study the shape, size, and arrangement of the monolith's channels, as well as other geometrical parameters of the structure. In doing so, one must assume the reaction as bulk mass transfer limited. Using this assumption, the effect of mass transfer dominates the overall kinetics of the reaction. The importance of designing the monolithic structure in the bulk mass transfer regime is that the size and other geometrical parameters of the monolithic structure discussed in Section 3.1 can be optimized using the knowledge in mass transfer fundamental parameters, for a required reaction conversion (Heck et al. 2009).

The reaction conversion correlation with the mass transfer parameters can be derived starting from a material balance across a plug-flow reactor by assuming a onedimensional steady-state operation, where the reactor is considered isothermal when the conversion is low (Heck et al. 2009).

$$
v \frac{d C}{d z}=-r
$$

where

$$
\begin{aligned}
& v=\text { velocity of reactant } \\
& C=\text { molar concentration of reactant } \\
& z=\text { length of reactor } \\
& r=\text { molar rate of reaction }
\end{aligned}
$$

Using the assumption of bulk mass transfer controlled reaction and an integration along the reactor length $(z)$, Equation (2) is solved for the reaction conversion $(X)$ by applying the definition of the mass transfer dimensionless numbers, yielding

$$
X=1-\exp \left[\frac{\left(S h_{\mathrm{ch}} \mathrm{a} / \varepsilon \mathrm{L}\right)}{\left(S c_{\text {monolith }} R e_{\text {monolith }}\right)}\right]
$$

where

Sherwood number in monolith's channel, $S h_{\mathrm{ch}}=K_{\mathrm{g}} \mathrm{d}_{\mathrm{ch}} / D_{A B}$

Schmidt number of monolith, $S c_{\text {monolith }}=D_{A B} u / \rho$

Reynolds number of monolith, $R e_{\text {monolith }}=(\mathrm{W} / \mathrm{A} \varepsilon) \cdot \mathrm{d}_{\mathrm{ch}} / \mu$

$K_{g}=$ mass transfer coefficient of reactant

$\mathrm{a}=$ geometric surface area per unit volume of monolith

$\mathrm{L}=$ length of monolith

$\mathrm{W}=$ total mass flow rate of the process gas to the cata-

lytic wall of monolith's channel

$\mathrm{A}=$ frontal area of monolith $\mathrm{d}_{\mathrm{ch}}=$ diameter of monolith's channel

$\varepsilon=$ void fraction of monolith

$D_{A B}=$ diffusivity of the reactant in monolith's channel

$\rho=$ process gas density at operating conditions

$\mu=$ process gas viscosity at operating conditions

Using Equation (3), a monolithic structure at an optimized CPSI of the geometrical parameters a, $\mathrm{L}, \mathrm{d}_{\mathrm{ch}}$, and $\varepsilon$ can be designed in order to achieve the best possible performance of the catalyst coated on the walls of the monolith's channels, for the highest possible conversion. This is because the optimized geometries of the monolithic structure in a bulk mass transfer limited regime will facilitate a uniform velocity and composition of the inlet flow of the process gas within each channel of the monolith's structure (Giroux et al. 2005). An example of optimized geometries of a monolith's structure was demonstrated by Jungreuthmayer et al. (2015), where an exceptionally low pressure drop and uniform flow pattern was exhibited in a computational fluid dynamics simulation of polymethacrylate-based monolith structure through alternate interconnecting arrangements between wide and narrow channels. Favorable permeability for effective transport of reactant molecules to the monolith's wall was observed.

In order to understand the advantage a monolithic catalytic structure has over the pelletized catalysts in a packed bed in terms of effective catalyst utilization, a definition of global effectiveness factor is introduced. This factor is dependent on the uniformity of the velocity and composition of the bulk flow of the process gas in the monolith's channels. The global effectiveness factor is defined as the ratio of the rate in the catalytic washcoat on the channel wall, to the rate at the mean bulk process gas concentration (Hayes et al. 2004).

Zamaniyan et al. (2011) described very small global effectiveness factors for the pelletized catalysts in the order of $10^{-2}$ which introduce a challenge when viewed from an economical perspective as only approximately $5 \%$ of the catalyst in the reformer tubes is effectively utilized. This challenge can be overcome in the monolithic catalytic support structure by the ability to optimize its geometries for an improved global effectiveness factor. A bed of randomly packed pelletized catalysts does not have the luxury of doing so.

\subsubsection{Diffusion of molecules of reactants/products in the pores}

In SMR, which is a diffusion-limited reaction (Zamaniyan et al. 2011), not only the bulk flow distribution of the 
process gas is imperative, but more importantly, the diffusion of reactants within the catalyst layer (Saito et al. 2015 ) is also crucial. Therefore, on top of designing a monolithic structure that is able to maintain low pressure drop operation (as a result of low bulk mass transfer resistance) and good mechanical strength, the selection of the washcoat material that is of high surface area for uniform and homogeneous active phase dispersion needs to also be given careful attention in order to achieve improved performance (Mohino et al. 2005).

The material of the washcoating layer on the wall of the monolith's channels is typically an oxide layer of $10-100 \mu \mathrm{m}$ thick. The diffusion of reactants and products occurs from/to the open gas phase through the nano/ micro-sized pores of the washcoat onto the catalytic metal nanoparticles surface in the washcoat layer, for the reaction to take place (Mladenov et al. 2010).

In the case of a diffusion-limited reaction, the socalled intra-phase mass transfer resistance occurs due to the slower intrinsic rate of diffusion of the molecules towards the active catalyst, in comparison to the intrinsic rate of reaction. This effect is characterized as the local effectiveness factor, which is defined as the ratio of the mean rate of reaction in the washcoat, to the rate of reaction at the external surface of the washcoat. An error in a reactor performance prediction can be introduced when neglecting the diffusion mass transfer resistance. This is especially critical for the SMR reaction, which has been established as a diffusion-limited reaction. Diffusion is insignificant at an effectiveness factor of unity. A factor beyond unity is observed in non-isothermal catalysts, while a value of less than unity indicates an occurrence of a diffusion limitation (Hayes et al. 2004).

In general, the typical porous oxide layer such as alumina and silica hinders the internal mass transfer due to a reduced pore volume and higher tortuosity. An alternative thin layer made of entangled carbon nanomaterials has been demonstrated to fulfil the requirement for effective internal mass transfer due to their increased pore volume and surface area with low tortuosity (Chinthaginjala et al. 2007). This was exhibited by Pd catalysts supported on a $\mathrm{CNF} / \mathrm{TiO}_{2}$ monolith developed by Zhu et al. (2015), where a high activity of Pd catalysts was observed based on reaction rates and intermediate product selectivity in nitrite hydrogenation and ethylbenzene oxidative dehydrogenation. The filamentous carbon layer has the potential to act as a surface textural promoter on a metal substrate surface that does not possess porosity as high as a ceramic, as discussed earlier in Section 3.2. The potential of carbon nanomaterials growth on metal monoliths as the surface textural promoter for well-dispersed and stabilized catalyst particles is a current research focus in our group.

The effect of diffusion also arises from the variations in the washcoat thickness on the channel walls. In a square monolith's channel, for instance, the washcoat thickness varies from the sides to the corners, as illustrated in Figure 6 (Zamaniyan et al. 2010). The thickness can be as low as $10 \mu \mathrm{m}$ at the sides but up to $150 \mu \mathrm{m}$ at the corners (Hayes et al. 2004, Zamaniyan et al. 2010). This thickness non-uniformity affects the mass transfer phenomena, which leads to non-uniform product distribution (Zamaniyan et al. 2010). An investigation of the effects of non-uniform washcoat thickness on the mass transfer aspects was reported extensively by Hayes et al. (2004). The simulation study was done based on the washcoating on a square channel that has thickness variations at the sides and the corners and a "sinusoidal" shaped channel that has the effect of a surface of a corrugated metal sheet. It was concluded from their findings that the washcoat thickness non-uniformity varied the Sherwood number $\left(S h_{\mathrm{ch}}\right)$ and hence the mass transfer coefficient $\left(D_{A B}\right)$ as represented by the Sherwood number correlation, which led to variations in the product concentration along the gas-solid interface, as represented by the mass transferconversion correlation in Equation (3).

\subsection{Effective heat transfer}

In energy intensive reactions, effective heat transfer is crucial (Peng and Richardson 2004). For an extended life of the reformer tubes, the tube wall temperature should

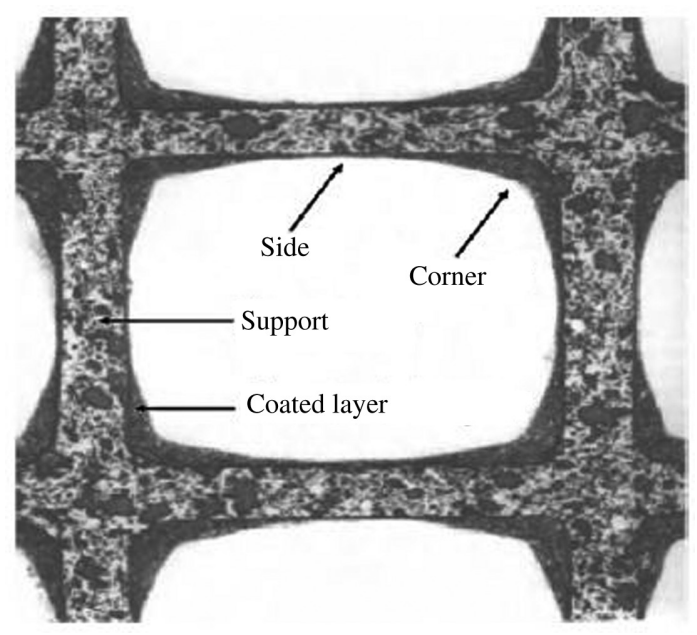

Figure 6: Illustration of non-uniformity of washcoat thickness on square channel's walls (Zamaniyan et al. 2010).

Reproduced with permission from Elsevier. 
be kept well below its maximum design value at all times (Mohammadzadeh and Zamaniyan 2002, Zamaniyan et al. 2011). Hot spots once started will propagate along tube axial length and lead to deactivation of the catalysts and consequently decrease the selectivity (Peng and Richardson 2004).

Monolithic support provides much greater heat conduction in comparison with a randomly packed bed of pelletized catalysts. In monolithic structure, the heat transfer mechanism through radial convection of gas may not exist, but the heat transport via conduction through the solid phase structure to the channels where the catalyst particles reside is more significant. The amount of heat conduction will depend on the properties of the selected substrate material and the adopted geometries (Groppi and Tronconi 2005), as similarly addressed for mass transfer enhancement.

The effective radial conductivity of a bare monolith structure $\left(k_{S, R}\right)$ made of a material of thermal conductivity $\left(k_{s}\right)$ with void fraction, $\varepsilon$ is also a function of the thermal conductivity of the process gas $\left(k_{G}\right)$. The correlation is presented by Boger and Heibel (2005), which was derived in an earlier work (Groppi and Tronconi 1996), neglecting the effect of radiative heat transfer (Roh et al. 2010):

$$
k_{S, R}=k_{S}\left((1-\sqrt{\varepsilon})+\frac{\sqrt{\varepsilon}}{\left(1-\sqrt{\varepsilon}+\frac{k_{G}}{k_{s}} \sqrt{\varepsilon}\right)}\right)^{-1}
$$

The convective heat exchange between the process gas flowing inside the channels and the channel wall is normally described by a film model due to the much smaller channel dimensions in comparison to the monolith diameter. The correlation is given using a heat transfer coefficient $\left(h_{G S}\right)$ and the corresponding Nusselt number of the channel $\left(N u_{\mathrm{ch}}\right)$ as shown below:

$$
h_{G S}=\frac{N u_{\mathrm{ch}} k_{G}}{\mathrm{~d}_{\mathrm{ch}}}
$$

For a laminar flow inside a small-hydraulic-diameter channel, the Nusselt number $\left(N u_{\mathrm{ch}}\right)$ is given by

$$
N u_{\mathrm{ch}}=0.571\left(\operatorname{Re} \frac{\mathrm{d}_{\mathrm{ch}}}{\mathrm{L}}\right)^{2 / 3}
$$

where $R e_{\text {ch }}$ is the Reynolds number of the process gas flowing inside the channel.

Theoretically, the washcoat layer and its thickness non-uniformity do have an effect on the $N u_{\mathrm{ch}}$. However, for design simplification, the contribution of the washcoat layer in an overall heat transfer coefficient can be assumed negligible due to its very small thickness in micrometer range. The correlation of the overall heat transfer coefficient for the calculation of thermal resistance or heat flux across the bare monolith in its radial direction can be developed using the information of the effective radial conductivity of the bare monolith $\left(k_{S, R}\right)$, the thermal conductivity of the process gas $\left(k_{G}\right)$, and the heat transfer coefficient for the convective heat exchange between the gas and the channel wall $\left(h_{G S}\right)$.

Based on Equation (4), using higher thermal conductivity material as the monolith substrate will definitely improve the heat flux and reduce the thermal resistance of the structure, but cost, weight, and various other factors discussed in Section 3.2 must also be taken into consideration while making the material selection. The heat transfer coefficient $\left(h_{G S}\right)$ in Equation (5) has a room for the heat flux improvement and the thermal resistance reduction through a careful optimization of the shape of the channel wall and the size of the channel.

Groppi and Tronconi (2000) developed temperature profiles based on the combined effect of monolith design parameters by simulating two different honeycomb configurations, shown in Table 2. Case 1 exhibited a higher average temperature profile, but a hot spot was predicted near the reactor inlet due to the monolith's higher void fraction $\varepsilon$, while Case 2 on the other hand exhibited near isothermal temperature profiles but lower average temperatures, as a result of the increased thickness of monolith wall represented by support fraction $\lambda$, and the higher thermal conductivity of the monolithic material improved the conductive heat transfer. However, it was also concluded from the findings that the lower catalyst temperature in the latter case resulted in a lower reactant conversion. This introduced a suggestion to simultaneously tune all the design parameters in order to optimize the catalyst temperatures and level of conversion.

As calculated by Giroux et al. (2005) for SMR at steady state, a high duty of external heat supply is required to the reformer tube. In other words, the substrate material of monolith structure construction dictates the thermal

Table 2: Monolith catalyst configurations used in the simulations by Groppi and Tronconi (2000).

\begin{tabular}{lll}
\hline & Case 1 & Case 2 \\
\hline Monoliths void fraction & $\varepsilon=0.57$ & $\varepsilon=0.41$ \\
Inert support volume fraction & $\lambda=0.23$ & $\lambda=0.34$ \\
Active phase volume fraction & $\xi=0.20$ & $\xi=0.25$ \\
Monoliths substrate material & $\mathrm{k}=30 \mathrm{~W} /(\mathrm{mK})$ & $\mathrm{k}=50 \mathrm{~W} /(\mathrm{mK})$ \\
conductivity & & \\
\hline
\end{tabular}


behavior of the reactor (Groppi and Tronconi 2000, Giroux et al. 2005). The substrate material selection is therefore crucial for an effective heat transfer to meet the heat supply requirement. Ceramic monoliths nearly behave like adiabatic reactors due to their thermally insulating properties. Metal monoliths on the other hand are not adiabatic and can readily transfer heat (Giroux et al. 2005). However, there has never been an investigation carried out to compare the heat transfer performance and conversion improvement between metal monoliths and ceramic monoliths.

Various investigations examining the effect of heat transfer effectiveness on improving the conversion in SMR by comparing a pelletized catalyst system and a monolithic catalysts system have been demonstrated. Ryu et al. (2007) demonstrated a 20\% improvement in methane conversion when utilizing a significantly lower amount of $\mathrm{Ni}$ catalysts of $3 \mathrm{~g}$ on FeCr alloy monoliths with no pressure drop, as compared with a higher amount of pelletized $\mathrm{Ni}$ catalysts of $17 \mathrm{~g}$. This indicates that even though active catalyst of a lower amount was used, the heat transfer efficiency was enhanced considerably by the application of the alloy monolithic support.

Other evidence that shares the same conclusions of improvement in heat transfer efficiency that results in increased SMR reaction conversion by the use of a monolithic catalytic system in comparison to pelletized catalyst system can be found in the literature, such as Flytzani-Stephanopoulos et al. (1986), Groppi and Tronconi (2000), and Roh et al. (2010), who investigated the use of metal monoliths, and Twigg and Richardson (2002) and
Peng and Richardson (2004) who presented the evidence based on $\alpha-\mathrm{Al}_{2} \mathrm{O}_{3}$ foams and reticulated ceramic foams, respectively.

In the experimental study by Roh et al. (2010), a comparison of the heat transfer performance on the natural gas steam reforming between a $\mathrm{Ru} / \mathrm{Al}_{2} \mathrm{O}_{3}$ catalyst-coated $\mathrm{FeCr}$ alloy monolith structure and a packed bed of pelletized $\mathrm{Ru} / \mathrm{Al}_{2} \mathrm{O}_{3}$ catalysts was performed. First, based on the methane conversion, the employed catalyst bed (i.e. the monolith and the packed bed) temperatures were found to have taken place at the thermodynamic equilibrium conditions. The catalyst bed equilibrium temperatures, $\mathrm{T}_{\text {Св,equi }}$ were then employed as the catalyst bed mean temperatures in the heat transfer performance experiments, varied in the range of 748 to $975 \mathrm{~K}$, at fixed GHSV of $31,000 \mathrm{~h}^{-1}$. As shown in Figure 7A, it was evident from the experimental findings that for the provision of the same amount of heat flux, the temperature gradient required from the furnace wall to the catalyst bed $\left(\mathrm{T}_{\mathrm{FW}}-\mathrm{T}_{\mathrm{CB}, \text { equi }}\right)$ in monolith bed is much smaller than that to the packed bed. The data from Figure 7A were then used to calculate the overall heat transfer coefficients (U) of both the catalyst beds, at the varied $\mathrm{T}_{\mathrm{CB}, \text { equi }}$ (Figure 7B). It was revealed that the $\mathrm{U}$ values were at all times higher in the monolithic bed than in the packed bed, when calculated at any same catalyst bed mean temperatures. Within the range of the studied $\mathrm{T}_{\mathrm{CB} \text {,equi }}$ values of 748 to $975 \mathrm{~K}$, the $\mathrm{U}$ values for the monolith bed varied between 0.35 and $0.65 \mathrm{~kW} /\left(\mathrm{m}^{2} \mathrm{~K}\right)$, much higher than those of for the packed bed, which were between 0.1 and $0.3 \mathrm{~kW} /\left(\mathrm{m}^{2} \mathrm{~K}\right)$.
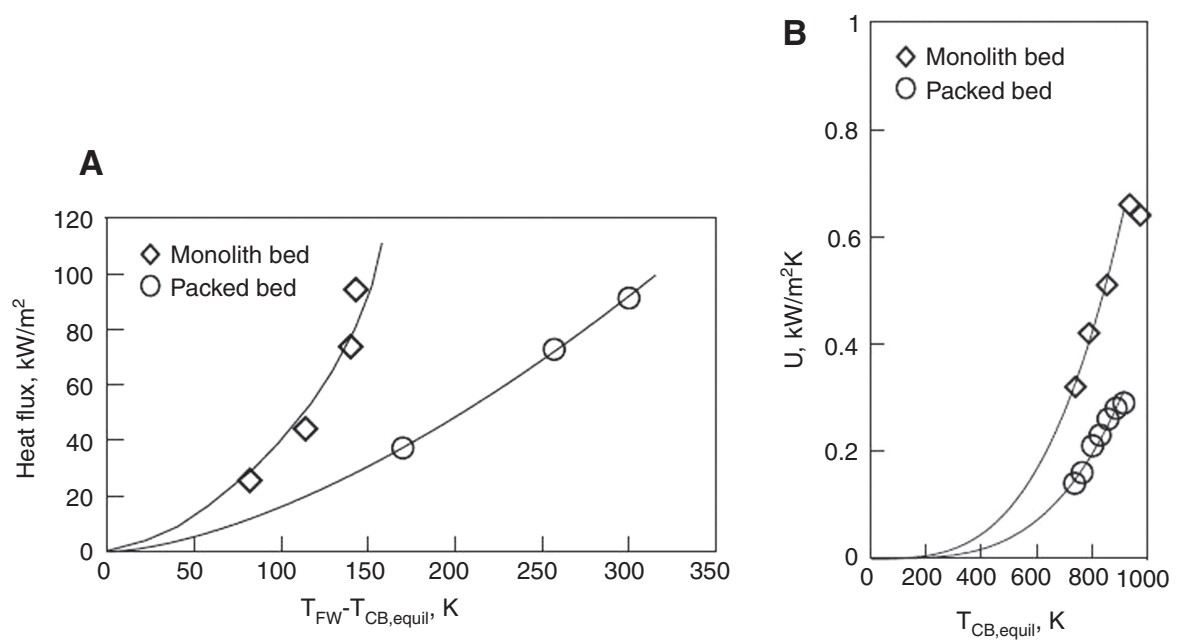

Figure 7: Heat transfer performance comparison of monolith bed and packed bed at varied catalyst bed mean temperatures and fixed GHSV of $31,000 \mathrm{~h}^{-1}$.

(A) Effect of the temperature gradient between the furnace wall and the catalyst bed on the heat flux across the catalyst bed; (B) overall heat transfer coefficients at different catalyst bed mean temperatures (Roh et al. 2010). Reproduced with permission from Elsevier. 
In recent developments, various studies have proven the use of microfibrous material (MFM) in making a metal structure with enhanced heat transfer characteristics (Tronconi et al. 2014). MFM is a high-porosity material made of sintered metal fibers of micron diameter (Sheng et al. 2011, 2012, 2013), which may potentially serve as a platform to develop MFM as a monolithic support, by entrapment of catalyst particles into the structure via an electroplating technique to form microfibrous entrapped catalyst (MFEC). MFECs in general provide high porosity volume, uniform distribution of catalyst particles, and high contacting efficiency, leading to enhanced mass and heat transfer. The improvement of radial conduction of sintered MFM is attributed to its sinter-locked network of microfibrous metal.

\subsection{Low pressure drop operation for the desired space velocity}

In any reactor, pressure drop is an important design parameter that needs to be given serious attention. Higher pressure drop translates to higher operation energy loss (Heck et al. 2001, Zamaniyan et al. 2011), as well as a loss of opportunity to run the reactor at higher capacity. Therefore, lower pressure drop operation is desirable in order to improve the system's energy efficiency and at the same time create the opportunity for higher space velocity by maximizing the process gas flow into the reactor, without a hydrodynamic instability issue (Roy et al. 2004).

In general, the lower pressure drop in the monolithic catalyst system is attributed to the OFA of the structure that is large enough to create little flow resistance. As far as design consideration is concerned, the pressure drop across the monolith structure is affected by the type of substrate material used. In comparison to ceramic monoliths of certain cell density, metal monoliths can be fabricated with a thinner wall structure due to better mechanical strength, thus creating larger open face surface areas that reduce the pressure drop (Giroux et al. 2005). The different shapes, diameters of the monoliths channels $\left(\mathrm{d}_{\mathrm{ch}}\right)$, and their arrangements, such as those developed by Zamaniyan et al. (2010) as shown earlier in Figure 1, or the various structures like foams, foils and felts, provide different pressure drop readings across the measured structures.

To date, no study has been published on characterizing and comparing the pressure drop readings across various monolith structures of different geometries experimentally. Richardson et al. (2000) presented in detail the procedures in measuring pressure drop across ceramic foams pelletized catalysts, which would be useful for adoption on a monolithic system. Nevertheless, the basic pressure drop correlation derived from the energy balance presented by Heck et al. $(2001,2009)$ can be adopted to calculate the pressure drop across the monolithic structure along its axial direction. The pressure drop $(\Delta \mathrm{P})$ equation is

$$
\Delta \mathrm{P}=\frac{2 f \mathrm{~L} \rho v_{\mathrm{ch}}^{2}}{g_{c} \mathrm{~d}_{\mathrm{ch}}}
$$

where

$f=$ dimensionless friction factor

$v_{\mathrm{ch}}=$ velocity in monolith's channel $=\mathrm{W} /(\rho \mathrm{A} \varepsilon)$

$g_{c}=$ gravitational constant

For the purpose of design, the expression in Equation (7) is useful in evaluating the options of monolith structures of various cell densities, wall thicknesses, and channel diameters, in relation to other design constraints such as space and compressor capacity (Heck et al. 2001).

On the basis of wet feed to steam reformer, the typical GHSV is typically between 5000 and $8000 \mathrm{~h}^{-1}$ and hence requires a large catalysts volume. While smaller catalyst pellets result in a better effectiveness factor, the pressure drop on the other hand increases across the large bed volume (Giroux et al. 2005). The lower pressure drop exhibited by monolithic structure as compared to pelletized catalyst in a packed bed has been discussed in previous sections. Bartholomew and Farrauto (2011) reported a pressure drop measurements across an equivalent volume of a pelletized catalyst bed and a 400 CPSI monolith at GHSV of $100,000 \mathrm{~h}^{-1}$. A pressure drop as high as 320 $\mathrm{kPa}$ was calculated for the former in comparison to as low as $2.67 \mathrm{kPa}$ measured for the latter.

A study by Zamaniyan et al. (2011) compared the pressure drop performance of a honeycomb monolithic structure with the actual plant data of a top fired steam methane reformer of Arak Petrochemical Complex in Iran, packed with a bed of four-channel-cylindrical-shaped pellet catalysts. From the plant data, the average pressure drop in one reformer tube was measured to be above 3 bar. On the other hand, by keeping the catalyst bed dimensions (diameter $=0.127 \mathrm{~m}$, length $=12.5 \mathrm{~m}$ ), total feed rate $(595 \mathrm{~kg} / \mathrm{h})$, natural gas to steam ratio (3.45:7.65), natural gas compositions, and all other operating parameters (inlet temperature $=520^{\circ} \mathrm{C}$, and inlet pressure $=15.4 \mathrm{bar}$ ) the same as the plant data, the pressure drop of the simulated honeycomb monolith was calculated to be less than $1 \mathrm{bar}$, which is about one order of magnitude lower than 
that of the packed bed. This clearly indicates the potential of energy saving in the monolithic catalytic system.

\subsection{Mechanical strength, packaging, and ease of loading into reformer tube}

\subsubsection{Mechanical strength}

Catalyst durability must be demonstrated to be robust for commercially significant period of time (Hochmuth 1992), for various reasons discussed earlier, such as exposure to high temperature gradients that tend to cause catalyst crushing leading to tube hot banding. Similarly, the monolithic structures must perform their intended function while maintaining their mechanical stability in the extremely high SMR reaction temperature of up to $1000^{\circ} \mathrm{C}$ (Whittenberger 2010).

Both ceramic and metal monoliths offer greater mechanical strength over discrete pellet catalysts (Giroux et al. 2005) due to their single-body structure that has better resistance to mechanical vibrations (Heck et al. 2001). Both monolithic and pelletized catalyst systems are subjected to the pressure caused by the weight of the stacked packed bed material. While both systems are exposed to harsh operation condition, such as high temperature and hasty temperature changes during operation shutdown and start-up, the pelletized catalysts supported typically by ceramic alumina can weaken and break due to the difference in the CTE in comparison with the reformer tube, leading to attrition and flow blockage, which results in a drop in activity and increase in pressure drop (Giroux et al. 2005). On the other hand, the uni-body monolithic structure will not easily break and crush. A metal monolith has a CTE comparable to the reformer tube, while a ceramic monolith such as cordierite has high resistance to thermal shock fracture as discussed earlier.

Heck et al. (2001) in their review paper listed the key mechanical properties for the monolithic support structure to possess which include parameters such as strength, Young's modulus, E-modulus, and fatigue. Tensile and compressive strength are key properties for the measure of the structure's ability to withstand loads of the packaging as well as high temperature gradients. E-modulus is the measure of stiffness or rigidity for determining the magnitude of thermal stress the structure is able to take, resulting from temperature gradients created by non-uniform velocity of the gas and the reaction's exotherms/isotherms, as well as thermal expansion mismatch between the reformer tubes and the catalyst structure. Lower
E-modulus is desirable as it represents longer life of the structure.

\subsubsection{Monolith packaging into tube}

In order to replace conventional pelletized catalyst system with structured monolithic catalytic system, the development of a new reactor loading concept is necessary. The effectiveness of packaging the monoliths into the tube determines the overall performance of heat transfer efficiency (Boger and Heibel 2005, Zamaniyan et al. 2011). A typical converter such as the exhaust of an automobile would have a package housed in a can made of stainless steel, consisting of a resilient mat holding the monolith structure and end seals for preventing the gas from bypassing or leaking inside a reactor shell (Heck et al. 2001, Giroux et al. 2005).

The heat needs to be transported across the gap between the monolith's outer surface and the reformer tube's inner surface to reach the catalytic surfaces. The gap $(\delta)$ introduces a resistance to heat transfer, in which its characterization is defined by gap size and also by the conduction through the stationary fluid film filling it, expressed in the form of heat transfer coefficient as inverse resistance. A typical temperature profile inside the monolith in a qualitative manner is shown in Figure 8 (Boger and Heibel 2005), where the profile in the gap is denoted by the number 2 .

For the laminar flow of the fluid film (in this case the process gases flowing through the gap), assumed to be steady and fully developed, the resistance to conductive heat transfer in the gap between the reformer tubes and the monoliths can be explained mathematically by using Nusselt number $\left(N u_{\text {gap }}\right)$ correlation. $N u_{\text {gap }}$ is defined as the ratio of convective to conductive heat transfer across the boundary (which is the surface) of the fluid film and the internal wall of the reformer tube (Subramanian 2015).

A heat transfer correlation for laminar flow is expressed as

$$
N u_{\text {gap }}=1.86 \operatorname{Re}_{\text {gap }}^{1 / 3} \operatorname{Pr}_{\text {gap }}^{1 / 3}\left(\frac{\delta}{\mathrm{L}}\right)^{1 / 3}\left(\frac{\mu_{b}}{\mu_{w}}\right)^{0.14}
$$

where Prandtl number in the gap,

$$
\operatorname{Pr}_{\text {gap }}=\frac{\mu_{w} C_{p}}{k_{w}} \text {, with } k_{w} \text { and } C_{p} \text { are the thermal }
$$

conductivity and the specific heat of the fluid film in the gap $(\delta)$ at constant pressure, respectively. 


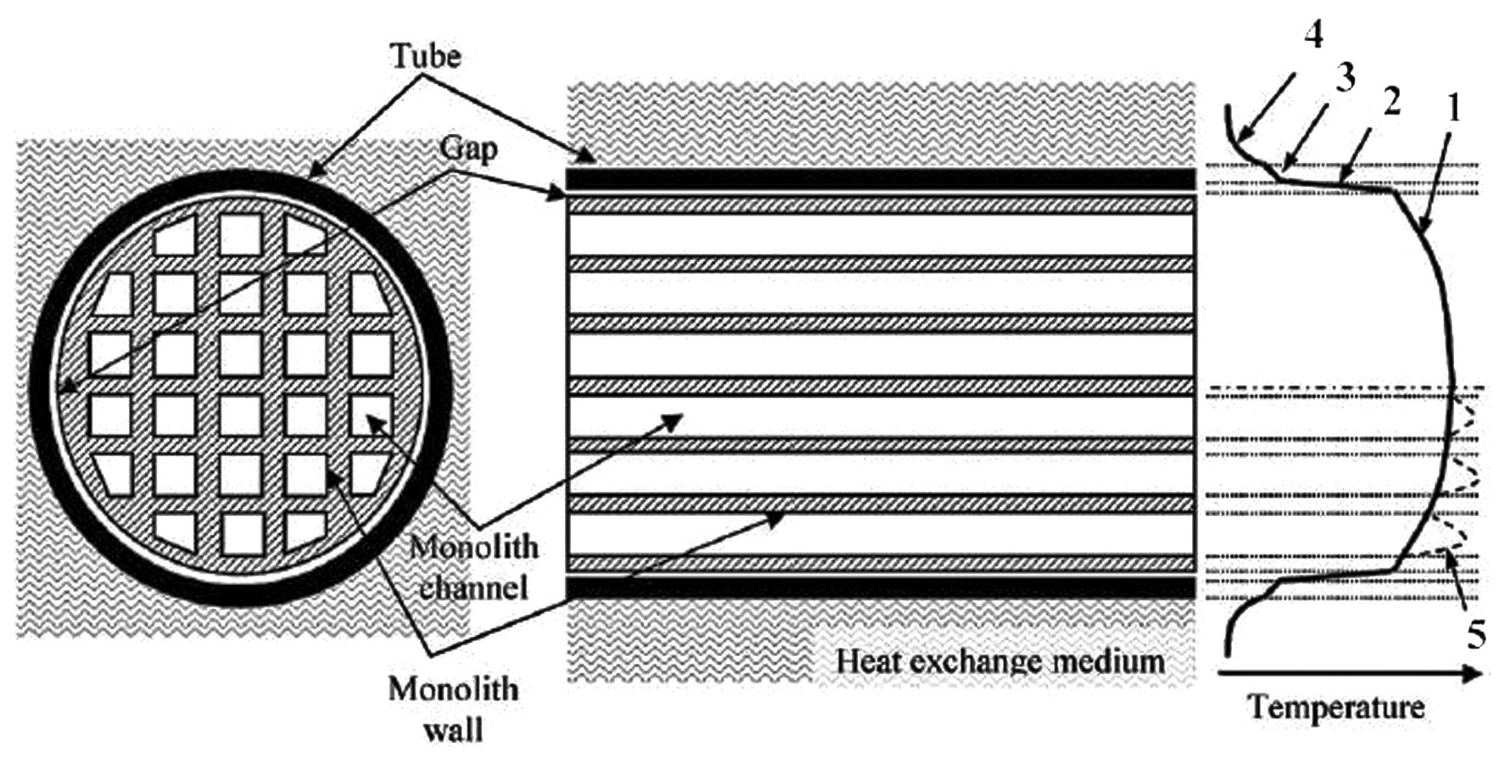

Figure 8: Typical temperature profile inside the monoliths residing in the tube (Boger and Heibel 2005).

Reproduced with permission from Elsevier.

The $\mu_{b} / \mu_{w}$ is the ratio of the viscosity of the bulk fluid in the reformer tubes and the viscosity of the fluid film next to the tube wall surface at any point in the axial direction. In this case here, only the fluid film filling the gap is considered. Therefore, $\mu_{b} \approx \mu_{w}$, and hence the ratio is approximated to be unity.

Based on the correlation given in Equation (8), the $N u_{\text {gap }}$ increases as the gap size $\delta$ increases. Therefore, heat convection by the flow of the molecules of the fluid film is greater than the heat transfer by conduction at an increased gap. Consequently, the resistance to the heat transfer by conduction from the reformer tube's internal wall to the monolith's outer surface increases.

The metal monoliths can be installed into the tube in two ways. It can either be welded into the tube and held permanently (Giroux et al. 2005) or housed in a metal shroud welded around it and placed inside the tube (Heck et al. 2001). Tronconi et al. (2004) in their work investigated the concept of "high conductivity monoliths" in an attempt to address the thermal resistance issue at the interface of the monolith and tube. They developed a prototype using a copper honeycomb structure which was tested by evaluating the overall heat transfer. Resistance to heat transfer at the interface was established by acknowledging the fact that effective removal/decrease of the resistance can be achieved by packaging the monoliths to reduce the gap between the monolith and the tube.

Temperature profile regression in a heat transfer experiment was conducted based on a one-dimensional model of a monolith reactor to estimate the heat transfer coefficient of the gap. The following heat transfer coefficients from the monoliths to the tube were obtained from the regression: $220 \mathrm{~W} /\left(\mathrm{m}^{2} \mathrm{~K}\right)$ for the system without special packaging, $400-500 \mathrm{~W} /\left(\mathrm{m}^{2} \mathrm{~K}\right)$ for the system with special packaging, and below $100 \mathrm{~W} /\left(\mathrm{m}^{2} \mathrm{~K}\right)$ for typical pelletized catalyst packing system (Tronconi et al. 2004). Based on the heat conductivity information presented in Table 1 earlier, the heat transfer coefficient across the reformer tube wall of a typical thickness of $15 \mathrm{~mm}$ made of IN519 is around $845 \mathrm{~W} /\left(\mathrm{m}^{2} \mathrm{~K}\right)$.

For ceramic monoliths, however, the packaging must be robust enough that it should provide positive holding pressure on the monoliths, for provision of adequate frictional forces at the monoliths/package interface to create resistance to vibration and back pressure loads, that if not present would cause monoliths slippage. The provision of holding pressure also creates symmetrical entry of inlet gases (Heck et al. 2001), thereby preventing bypass of unreacted gases around the monolith.

For this purpose, a packaging made of ceramic material is placed in the gap to provide the gripping force to strongly hold the monoliths during low and high temperature cycles as well as to ensure gas flows through the monolithic structure instead of through the gap. Upon heating, expansion of this ceramic packaging material secures the monoliths firmly within the tube. However, at temperatures above $800^{\circ} \mathrm{C}$, gradual degradation may occur, losing its gripping force and hence increased bypass flow in between the monolith structure and the tube. Therefore, for operations requiring temperatures over $800^{\circ} \mathrm{C}$, selection of ceramic fiber capable of withstanding high temperature must be considered (Giroux et al. 2005). 
In the work by Boger and Heibel (2005), honeycomb structures made of materials with high thermal conductivity were simulated focusing on the heat transfer effectiveness of the structures packaged in heat exchanger tubes by varying the substrate material types (aluminium, copper, and cordierite) and gap tolerances. Heat transfer performance is better at reduced gap clearance due to lower thermal resistance. However, an optimized balance needs to be met between improving the performance of heat transfer through a reduced gap size and ease of loading the monoliths into the tube. Too small a clearance would require some pushing force (Boger and Heibel 2005) that might affect the structure.

Exploring fabrication technology that can construct the monolith together with the tube without a gap will introduce significant advantages in terms of overall heat transfer performance and structural integrity. Additive manufacturing and rapid prototyping technologies to fabricate three-dimensional structure from CAD developed models may be worth exploring. These processes offer the capability to construct geometrically complex structures by the gradual addition of materials (Kruth et al. 1998, Guo and Leu 2013). Three-dimensional printing (3DP) is one of the additive manufacturing methods that is capable of fabricating the structures of both metal and ceramic materials (Guo and Leu 2013).

\subsubsection{Monolith supports stacking}

Zamaniyan et al. (2010) described and presented the proper way of loading the monolith structure in the tube. The structure was wrapped around with a metal sheath for easy fitting inside the tube, shown in Figure 9.

In addition to addressing the loading of monolith structure into the tube, Zamaniyan et al. (2010) also recognized the fact that there is another disadvantage that prevents monolithic catalysts from finding extensive applications in the industry, which is the stacking of the monoliths on top of each other. Therefore, another feature called tails was introduced, as shown in Figure 9, which acts as a spacer between two adjacent monoliths to match and align the channels of the top and the bottom monolith structures preventing some channels from getting covered.

Furthermore, the tails create the space between the top and bottom monolith structures, which allow mixing and redistribution of the flow exiting the channels. This creates an almost uniform reaction conversion, product selectivity, and temperature profile through each of the channels. The proposed concept allows the possibility of

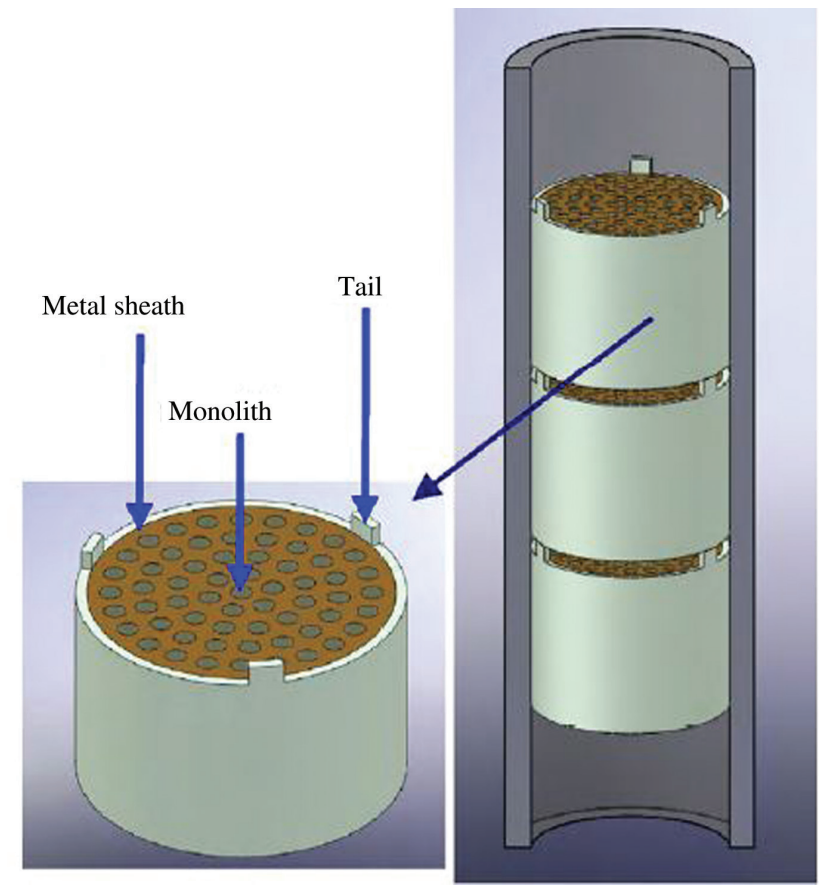

Figure 9: Proposed concept of monoliths loading inside reactor tube by Zamaniyan et al. (2010).

Reproduced with permission from Elsevier.

introducing additional feed gases at any various points in the axial direction of the tube, hence making product yield and selectivity enhancements easier in comparison to the typical packed bed of pelletized catalysts.

Some disadvantages were identified by Zamaniyan et al. (2010), and suggestions for improvement were presented accordingly. One of them is lower heat transfer caused by the space between the monoliths, but this can be overcome by having a tube of larger volume. Alternatively, the drop in heat transfer effectiveness may be minimized by filling the spacers with a heat carrier that is inert to the reaction. This is indeed a very similar approach used in large-diameter reactors where inter-stage cooling or heating is introduced by installing coils in the internal reactor space. However, there is a pressure drop penalty associated with this approach due to entrance and exit head losses associated with the coils.

\section{Conclusions}

Steam reforming requires a constant supply of heat for the reaction to proceed efficiently. This is restricted by the ineffective heat transfer and limited external surface area to reach active catalytic sites. In a pelletized catalyst system, the heat is transferred from the catalyst pellets 
near the tube wall to the catalyst residing in the tube center via ineffective convection of the process gas. Heat conduction via point-wise contact is almost negligible.

Further development of compact reformers, for such applications as hydrogen fuel stations or fuel cells, will require an optimized balance of crucial parameters such as heat transfer and mass transport effectiveness, while keeping the pressure drop of the reactor below a threshold value for the desired GHSV and throughput. Consideration for capital and operating costs must also be made. In the reforming section of an industrial-scale plant, the main challenge is the undesired carbon formation during certain process upsets and unfavorable conditions leading to catalyst breakage and, hence, excessive heating of reformer tubes resulting in hot bands that are fatal to tube lifetime. Additionally, the catalyst loses its activity, and hence the reforming conversion will be non-optimal.

Therefore, monolithic catalytic structures have been investigated by various researchers as a potential future system for SMR. There is potential to exploit their advantages of enhanced conductive radial heat transfer due to their single-body structure, low pressure drop through the introduction of the channels, good mechanical strength for operation under aggressive reaction condition, and improved performance of mass transfer due to higher availability of specific surface area.

In the design of monolithic structures, the substrate material of choice must meet the requirement of high surface area in order to achieve uniform and homogeneous active phase dispersion for improved performance, while maintaining low pressure drop operation and good mechanical strength. Metal monoliths offer the possibility of fabricating a structure with a large OFA that introduces lower pressure drop, as compared to ceramic monoliths due to the enhanced mechanical properties of metals. However, the porosity of a metal substrate surface is lower than that of a ceramic material and hence requires coating with a compatible layer of high specific surface area to facilitate high dispersion of active metal catalyst particles. One possible way of doing this is by growing a filamentous carbon layer on the surface of the monoliths as textural promoter to satisfy the requirements for high porosity and low tortuosity to increase the effectiveness of the surface area.

The thermal resistance between the reformer tube and the monolith structure due to the gap requirement for packaging into the reformer tube has been identified as the main heat transfer bottleneck. An optimized balance needs to be met between achieving enhanced heat transfer effectiveness by gap size reduction at the interface of the monolith outer wall and the tube internal wall, and ease of loading into the tube. Exploring fabrication technology such as 3DP that can construct the monolithic structure together with the tube without any gap would introduce significant advantage in terms of overall heat transfer performance.

A feature acting as a spacer that carries the roles of helping to align the channels of the monoliths stacking on each other needs to also be taken into consideration since packaging extremely long monoliths into reformer tubes is not practical. The spacers have to be designed in such a way that the channels of the top and bottom monolith structures allow continuous process gas flow, as well as making mixing and redistribution of the flow exiting the channels possible, in order to create a uniform temperature profile through each of the channels. A proper design of the spacer is required in order to modify the decreased heat transfer, such as to fill the spacers with a catalytically inert heat carrier.

Acknowledgments: We acknowledge the financial support of the Department of Chemical and Process Engineering, University of Canterbury, New Zealand.

\section{References}

Askeland DR, Fulay PP, Wright WJ. Mechanical properties: part two. In: The science and engineering of materials, 6th ed., Stamford, USA: Global Engineering, 2010: 260-265.

Auerkari P. Mechanical and physical properties of engineering alumina ceramics. Finland: Technical Research Centre of Finland, 1996: 5-26.

Baharudin L, Watson MJ. Hydrogen applications and research activities in its production routes through catalytic hydrocarbon conversion. Rev Chem Eng 2017; ahead of print March 7, 2017: https://doi.org/10.1515/revce-2016-0040.

Bartholomew CH, Farrauto RJ. Chapter 2: catalyst materials, properties and preparation. In: Fundamentals of industrial catalytic processes. Hoboken, New Jersey: John Wiley \& Sons, 2011.

Basile F, Benito P, Del Gallo P, Fornasari G, Gary D, Rosetti V, Vaccari A. Highly conductive Ni steam reforming catalysts prepared by electrodeposition. Chem Commun 2008; 25: 2917-2919.

Boger T, Heibel AK. Heat transfer in conductive monolith structures. Chem Eng Sci 2005; 60: 1823-1835.

Chinthaginjala JK, Seshan K, Lefferts L. Preparation and application of carbon-nanofiber based microstructured materials as catalyst supports. Ind Eng Chem Res 2007; 46: 3968-3978.

Chinthaginjala J, Thakur D, Seshan K, Lefferts L. How carbonnano-fibers attach to Ni foam. Carbon 2008; 46: 1638-1647.

Czuppon TA, Knez SA, Newsome DS. In: A. Bisio, S. Boots, editors. Encyclopedia of energy technology and the environment. New York: John Wiley \& Sons, 1995: 1752-1782.

Echave F, Sanz O, Velasco I, Odriozola J, Montes M. Effect of the alloy on micro-structured reactors for methanol steam reforming. Catal Today 2013; 213: 145-154. 
Flytzani-Stephanopoulos M, Voecks GE, Charng T. Modelling of heat transfer in non-adiabatic monolith reactors and experimental comparisons of metal monoliths with packed beds. Chem Eng Sci 1986; 41: 1203-1212.

Giroux T, Hwang S, Liu Y, Ruettinger W, Shore L. Monolithic structures as alternatives to particulate catalysts for the reforming of hydrocarbons for hydrogen generation. Appl Catal B-Environ 2005; 56: 95-110.

Groppi G, Tronconi E. Continuous vs. discrete models of nonadiabatic monolith catalysts. AIChE J 1996; 42: 2382-2387.

Groppi G, Tronconi E. Design of novel monolith catalyst supports for gas/solid reactions with heat exchange. Chem Eng Sci 2000; 55: 2161-2171.

Groppi G, Tronconi E. Honeycomb supports with high thermal conductivity for gas/solid chemical processes. Catal Today 2005; 105: 297-304.

Guo N, Leu MC. Additive manufacturing: technology, applications and research needs. Front Mech Eng 2013; 8: 215-243.

Hayes R, Liu B, Moxom R, Votsmeier M. The effect of washcoat geometry on mass transfer in monolith reactors. Chem Eng Sci 2004; 59: 3169-3181.

Haynes International. Retrieved from https://www.haynesintl.com/ alloys/alloy-portfolio_(accessed30.01.17).

Heck RM, Gulati S, Farrauto RJ. The application of monoliths for gas phase catalytic reactions. Chem Eng J 2001; 82: 149-156.

Heck RM, Farrauto RJ, Gulati ST. Catalytic air pollution control: commercial technology. Hoboken, New Jersey: John Wiley \& Sons, 2009: 63-77.

Hochmuth JK. Catalytic partial oxidation of methane over a monolith supported catalyst. Appl Catal B-Environ 1992; 1: 89-100.

HyperPhysics. Georgia State University, Atlanta, Georgia 30302-5060. Retrieved from http://hyperphysics.phy-astr.gsu. edu/hbase/hph.html (accessed 30.01.17).

INCO Europe Limited (1976). INCO Databooks. IN-519 Cast Chromium-Nickel-Niobium Heat-Resisting Steel <https:// www.nickelinstitute.org/ /media/Files/TechnicalLiterature/ IN_519CastChromium_Nickel_NiobiumHeat_ResistingSteel_ EngineeringProperties_4383_.ashx> (accessed 30.01.17).

Jungreuthmayer C, Steppert P, Sekot G, Zankel A, Reingruber $\mathrm{H}$, Zanghellini J, Jungbauer $\mathrm{A}$. The 3D pore structure and fluid dynamics simulation of macroporous monoliths: High permeability due to alternating channel width. J Chromatogr A 2015; 1425: 141-149.

Kruth J-P, Leu M-C, Nakagawa T. Progress in additive manufacturing and rapid prototyping. CIRP Ann Manuf Technol 1998; 47: 525-540.

Martinez AT, Camerucci M, Cavalieri A. Thermal stress analysis of cordierite materials subjected to thermal shock. J Mater Sci 2008; 43: 2731-2738.

Material Properties Charts. (2013). Ceramic Industry Magazine. Retrieved from http://www.ceramicindustry.com/ceramicmaterials-properties-charts (accessed 30.01.17).

Materials Data Book. (2003). Cambridge University Engineering Department. <http://www-mdp.eng.cam.ac.uk/web/library/ enginfo/cueddatabooks/materials.pdf> (accessed 30.01.17).

Mei H, Li C, Ji S, Liu H. Modeling of a metal monolith catalytic reactor for methane steam reforming-combustion coupling. Chem Eng Sci 2007; 62: 4294-4303.

Mladenov N, Koop J, Tischer S, Deutschmann O. Modeling of transport and chemistry in channel flows of automotive catalytic converters. Chem Eng Sci 2010; 65: 812-826.
Mohammadzadeh JS, Zamaniyan A. Catalyst shape as a design parameter - optimum shape for methane-steam reforming catalyst. Chem Eng Res Des 2002; 80: 383-391.

Mohino F, Martin AB, Salerno P, Bahamonde A, Mendioroz S. High surface area monoliths based on pillared clay materials as carriers for catalytic processes. Appl Clay Sci 2005; 29: 125-136.

Nijhuis TA, Beers AE, Vergunst T, Hoek I, Kapteijn F, Moulijn JA. Preparation of monolithic catalysts. Catal Rev 2001; 43: 345-380.

Peng Y, Richardson JT. Properties of ceramic foam catalyst supports: one-dimensional and two-dimensional heat transfer correlations. Appl Catal A-Gen 2004; 266: 235-244.

Rallan C, Garforth A. Growth of hierarchically structured high-surface area alumina on FeCralloy ${ }^{\circledast}$ rods. Chin J Chem Eng 2014; 22: 861-868.

Richardson JT, Peng Y, Remue D. Properties of ceramic foam catalyst supports: pressure drop. Appl Catal A-Gen 2000; 204: 19-32.

Roh H-S, Lee DK, Koo KY, Jung UH, Yoon WL. Natural gas steam reforming for hydrogen production over metal monolith catalyst with efficient heat-transfer. Int J Hydrogen Energ 2010; 35: 1613-1619.

Roy S, Bauer T, Al-Dahhan M, Lehner P, Turek T. Monoliths as multiphase reactors: a review. AIChE J 2004; 50: 2918-2938.

Ryu J-H, Lee K-Y, La H, Kim H-J, Yang J-I, Jung H. Ni catalyst wash-coated on metal monolith with enhanced heat-transfer capability for steam reforming. J Power Sources 2007; 171: 499-505.

Saito M, Kojima J, Iwai H, Yoshida H. The limiting process in steam methane reforming with gas diffusion into a porous catalytic wall in a flow reactor. Int J Hydrogen Energ 2015; 40: 8844-8855.

Sheng M, Yang H, Cahela DR, Tatarchuk BJ. Novel catalyst structures with enhanced heat transfer characteristics. J Catal 2011; 281: 254-262.

Sheng M, Yang H, Cahela DR, Yantz Jr WR, Gonzalez CF, Tatarchuk BJ. High conductivity catalyst structures for applications in exothermic reactions. Appl Catal A-Gen 2012; 445-446: 143-152.

Sheng M, Cahela DR, Yang H, Gonzalez CF, Yantz Jr WR, Harris DK, Tatarchuk BJ. Effective thermal conductivity and junction factor for sintered microfibrous materials. Int J Heat Mass Tran 2013; 56: 10-19.

Special Metals Corporation. Retrieved from http://www. specialmetals.com/products (accessed 30.01.17).

Subramanian RS. (2015) Heat transfer in flow through conduits. Department of Chemical and Biomolecular Engineering, Clarkson University Project $<$ http://people.clarkson.edu/ projects/subramanian/ch330/notes/Heat\%20Transfer\%20 in\%20Flow\%20Through\%20Conduits.pdf> (accessed 30.01.17).

Tonkovich AY, Perry S, Wang Y, Qiu D, LaPlante T, Rogers WA. Microchannel process technology for compact methane steam reforming. Chem Eng Sci 2004; 59: 4819-4824.

Tronconi E, Groppi G, Boger T, Heibel A. Monolithic catalysts with 'high conductivity' honeycomb supports for gas/solid exothermic reactions: characterization of the heat-transfer properties. Chem Eng Sci 2004; 59: 4941-4949.

Tronconi E, Groppi G, Visconti CG. Structured catalysts for non-adiabatic applications. Curr Opin Chem Eng 2014; 5: 55-67. 
Twigg M, Richardson J Theory and applications of ceramic foam catalysts. Chem Eng Res Des 2002; 80: 183-189.

Visconti CG, Groppi G, Tronconi E. Highly conductive "packed foams": A new concept for the intensification of strongly endo-and exo-thermic catalytic processes in compact tubular reactors. Catal Today 2016; 273: 178-186.

Whittenberger WA. (2010) Permanent, high performance, drop-in replacement catalyst for steam reforming hydrogen plants. In: C. Corporation (Ed.), Stackable structural reactor $\left(\mathrm{SSR}^{\circledR}\right)$ Technology White Paper (Vol. 102).

Zamaniyan A, Mortazavi Y, Khodadadi AA, Manafi H. Tube fitted bulk monolithic catalyst as novel structured reactor for gas-solid reactions. Appl Catal A-Gen 2010; 385: 214-223.

Zamaniyan A, Khodadadi AA, Mortazavi Y, Manafi H. Comparative model analysis of the performance of tube fitted bulk monolithic catalyst with conventional pellet shapes for natural gas reforming. J Ind Eng Chem 2011; 17: 767-776.

Zhu J, Wu F, Li M, Zhu J, van Ommen JG, Lefferts L. Influence of internal diffusion on selective hydrogenation of 4-carboxybenzaldehyde over palladium catalysts supported on carbon nanofiber coated monolith. Appl Cataly A-Gen 2015; 498: 222-229.

\section{Bionotes}

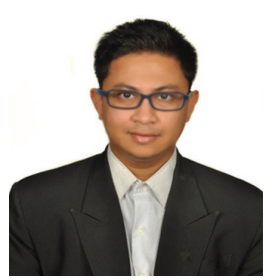

\author{
Luqmanulhakim Baharudin \\ Department of Chemical and Process \\ Engineering, College of Engineering, \\ University of Canterbury, Private Bag 4800, \\ Christchurch 8140, New Zealand
}

Luqmanulhakim Baharudin joined the Department of Chemical and Process Engineering, University of Canterbury in May 2016 as a PhD candidate. He earned his MPhil in Advanced Chemical Engineering Practice from the University of Cambridge, UK. He has had approximately 10 years of significant international industrial experience in the petrochemical industry working for Haldor-Topsoe, Petronas, and ExxonMobil. He is currently developing a monolithic catalytic system for steam methane reforming and water gas shift reactions.

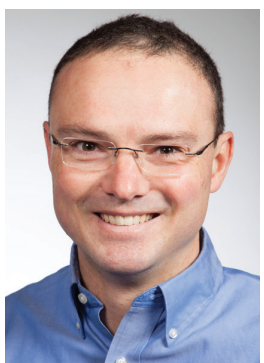

\section{Matthew James Watson}

Department of Chemical and Process Engineering, College of Engineering, University of Canterbury, Private Bag 4800 , Christchurch 8140, New Zealand, matthew.watson@canterbury.ac.nz

Matthew James Watson joined the Department of Chemical and Process Engineering, University of Canterbury, in 2015 as an Associate Professor, after more than 15 years of applied R\&D experience at Air Products and Chemicals Inc., Pennsylvania. He earned his BE degree from the University of Canterbury in New Zealand and his MSc and PhD from Lehigh University, USA. His research interest is in developing and investigating novel materials such as structured catalyst and adsorbent supports, high-temperature electrolytic reduction of metals, new applications for oxy-fuel combustion, and oxygen generation from waste heat. 